SEFARAD, vol. 80:1, enero-junio 2020, págs. 203-261

ISSN: 0037-0894, https://doi.org/10.3989/sefarad.020-007

\title{
La pequeña comunidad hebrea de La Línea (1856-1936)*
}

\author{
José María Lázaro Bruña** \\ IES Virgen de la Esperanza, La Línea (Cádiz) \\ ORCID ID: https://orcid.org/0000-0002-3263-5794
}

\begin{abstract}
A partir de la segunda mitad del siglo XIX un puñado de familias hebreas provenientes del norte de África o de Gibraltar se estableció en La Línea, una ciudad fronteriza con la colonia británica. Esta presencia hebrea se intensificó tras la guerra hispanomarroquí de 1859, cuando se produjo un paulatino movimiento migratorio de los judíos del norte de África hacia España. Muchos de ellos recalaron en las plazas de soberanía españolas de África, pero una parte de ellos cruzó el estrecho y se asentó en la colonia británica de Gibraltar y en la ciudad fronteriza de La Línea donde ya vivían algunas familias. Todos estos hebreos conformaron una pequeña comunidad cuya presencia se prolongó hasta los inicios de la Guerra Civil española cuando la mayoría de la comunidad judía establecida en La Línea abandonó la ciudad.
\end{abstract}

Palabras ClaVe: España; judíos; sinagoga; cementerio.

The Small Hebrew Community of La Línea (1856-1936).- From the second half of the nineteenth century a few Hebrew families from Gibraltar or from North Africa settled on La Línea, a border town next to the British colony of Gibraltar. This Hebrew presence intensified after the Spanish-Moroccan war of 1859, when there was a gradual migratory movement of Jews from North Africa to Spain. Many of them remained on the Spanish cities of Africa, but a part of them crossed the Strait and settled in the British colony of Gibraltar and also in this border city of La Línea where some families already lived. These Hebrews formed a small community whose presence lasted until

* Siglas utilizadas: Archivo Histórico Municipal Francisco Tornay de La Línea (AHMFT), Archivo Histórico Provincial de Cádiz (AHPC), Archivo Municipal de San Roque (AMSR), Archivo Parroquial Santa María la Coronada de San Roque (APSMC), BOP (Boletín Oficial de la Provincia de Cádiz), CDMH (Centro Documental de la Memoria Histórica), Gibraltar National Archives (GNA), Instituto Nacional de Estadística (INE), The National Archives (TNA). Asimismo, téngase en cuenta que, en aras de la claridad del discurso, tanto en el título como a lo largo del artículo, el término comunidad alude a los judíos de La Línea de manera genérica como 'conjunto de personas vinculadas por características o intereses comunes' y no de forma específica referida a un grupo organizado.

** jlazbru106@gmail.com

Copyright: (C) 2020 CSIC. Este es un artículo de acceso abierto distribuido bajo los términos de la licencia de uso y distribución Creative Commons Reconocimiento 4.0 Internacional (CC BY 4.0). 
the beginning of the Spanish Civil War when most of the Hebrew community stablished in La Linea left the city.

KeYwords: Spain; Jews; Synagogue; Cemetery.

\section{INTRODUCCIÓN}

Desde el punto de vista legal, la comunidad judía española volvió a tener carta de naturaleza a raíz de la revolución de 1868. Fue en aquel momento y gracias a la constitución surgida de la Gloriosa cuando se autorizó la libertad religiosa para todos los ciudadanos españoles de una manera clara:

El ejercicio público o privado de cualquier otro culto queda garantido a todos los extranjeros residentes en España, sin más limitaciones que las reglas universales de la moral y el derecho. Si algunos españoles profesaren otra religión que la católica, es aplicable a los mismos todo lo dispuesto en el párrafo anterior ${ }^{1}$.

Este artículo permitía en la práctica el regreso de los judíos a España. $\mathrm{Y}$, efectivamente, a partir de este año algunos hebreos de Oriente y del norte de África, amparándose en ese artículo de la nueva constitución, comenzaron a volver a su antigua patria. La primera nacionalización que encontramos en la Gaceta es la de David Cohen, un hebreo natural de Tánger, al que se le concede en ese mismo año de 1869: a este siguió un pequeño de reguero de nacionalizaciones de judíos provenientes del norte de África y de Oriente que se extiende hasta finales del siglo XIX $\mathrm{y}$ comienzos del $\mathrm{xx}^{2}$.

Algunos de ellos se establecieron permanentemente en España, conformando pequeñas comunidades hebreas como las de Ceuta o Melilla

1 Artículo 21 de la Constitución de 1869 (Gaceta de Madrid, núm. 158, de 07/06/1869, págs. 1-2).

2 La nacionalización de David Cohen aparece en la Gaceta de Madrid, núm. 328, de 24/11/1869, pág. 1. Para la naturalización de los judíos provenientes del norte de África, véase Maite OJEDA MATA, «Protección y naturalización española de judíos en el Marruecos colonial», en Los judios en Ceuta, el norte de África y el Estrecho de Gibraltar, XVI Jornadas de Historia de Ceuta (Ceuta: Instituto de Estudios Ceutíes, 2014) págs. 277-300. 
en el norte de África mientras que en la península surgen otras como la comunidad de Madrid que aparece a mediados del siglo XIX o la comunidad de Sevilla que se inicia en torno a $1860^{3}$. Sin embargo, pocos años antes que estas colonias se asentaran en la península, ya existía en el punto de La Línea, junto a la colonia británica de Gibraltar, una pequeña comunidad hebrea que dataría, al menos, del año 1856.

\section{LA VILLA DE LA LÍNEA}

Después del último sitio de Gibraltar (1779-1783) surgió, tras la línea de fortificaciones que circunvalaba la plaza desde 1730, un pequeño pueblo que medró poco a poco surtiendo de hortalizas y fruta fresca a la población de Gibraltar. Cuando esta línea de circunvalación fue destruida por las tropas británicas en 1810 durante la Guerra de la Independencia, este pueblo comenzó a crecer rápidamente a la sombra de la colonia británica. A mediados del siglo XIX el cronista sanroqueño Lorenzo Valverde describía la pequeña población de este modo:

Así le llamamos á un Pueblecito que hay en el sitio por donde precisamente se debe entrar en Gibraltar. [...] Habrá unos [...] vecinos los más de ellos pasan con tiendas de Comestibles y de bebidas, dos Cafees y una Mesa de Villar, tres o cuatro posadas, panaderías y Algunos Artesanos $^{4}$.

Tal y como afirma este autor, era por el rastrillo de la arruinada línea de contravalación por donde se efectuaba el paso a la plaza de Gibraltar y era este el camino que ponía en contacto a los hebreos gibraltareños con España: fue por allí por donde pasaron durante la primera mitad del siglo XIX algunos de ellos con el propósito de convertirse y establecerse en España. El caso más conocido es el de la gibraltareña Simi Cohen, una hebrea que en 1817 huyó a La Línea y de allí a Medina Sidonia

3 Julio Caro Baroja, Los judios en la España Moderna y Contemporánea, Tomo III (Madrid: Ediciones Istmo, 1986) págs. 207 y 222.

${ }^{4}$ Lorenzo Valverde, Carta histórica y situación geográfica de la Ciudad de San Roque y términos de su demarcación en el Campo de Gibraltar. Textos recopilados y anotados por F. y E. Cano Villalta (Cádiz: Instituto de Estudios Campogibraltareños, 2003) pág. 87. 
donde se bautizó e ingresó en el convento de las Agustinas Recoletas, pasando el resto de su vida como la hermana Amor de Dios ${ }^{5}$. A esta siguieron otros como Abraham Bendallán en 1818, un hebreo natural de Tetuán y procedente también de Gibraltar que solicitó que se le admitiese a la religión católica y al año siguiente hizo lo propio Abraham Belice, otro hebreo de veintitrés años de la misma naturaleza y vecindad, pidiendo ser admitido en el rebaño cristiano; este se unió en Gibraltar a Romualdo Bermullun, otro hebreo de la colonia, y ambos pasaron la frontera y pidieron bautismo cristiano ${ }^{6}$. Estas continuas deserciones de hebreos hicieron que, en agosto de 1819, el rey Fernando VII recordara a todos sus súbditos, mediante una real orden, qué es lo que debían hacer cuando ocurriese tal cosa:

Enterado el Rey nuestro Señor de que un número considerable de hebreos procedentes de Gibraltar, Tetuán y otros puntos arriban á los puertos de Andalucía, especialmente á Cádiz, Algeciras y Sevilla, presentándose al tribunal del Santo Oficio con pasaportes de las Autoridades civiles solicitando la abjuración de sus errores, sin embargo de que está prohibido que ningún judío pueda saltar en tierra ni internarse en estos dominios con pretexto alguno sin obtener antes el correspondiente Real permiso; se ha servido S. M. mandar, con presencia de lo dispuesto en Real orden de 25 de Abril de 1786, y Real cédula de 8 de Junio de 1802, que se expidan las convenientes ordenes á los Capitanes generales, Gobernadores y Justicias de los puertos y fronteras, y á los demás á quienes corresponda, á fin de que no permitan saltaren tierra ni internarse en estos dominios á ningún hebreo sin preceder el permiso de S. M., y el aviso correspondiente al Fiscal de Inquisición, donde le hubiere, y donde no á sus Ministros, para que puedan zelar y observar la persona y acciones del individuo á quien se conceda aquella licencia en la forma acostumbrada ${ }^{7}$.

5 Véase Martín Bueno Lozano, Simi Cohen: gibraltareña, judia y monja (Chiclana: Industrias Gráficas Lipper, 1989).

${ }^{6}$ Antonio Paz y Meliá, Papeles de Inquisición. Catálogos y extractos. Segunda edición, por Ramón Paz (Madrid: Patronato del Archivo Histórico Nacional, 1947) pág. 62. Para el destino de ambos, véase Juan Bautista VILAR, Tetuán en el resurgimiento judio contemporáneo (1850-1870): aproximación a la historia del judaísmo norteafricano (Caracas: Asociación Israelita de Venezuela, 1985) págs. 193-200.

7 Fernando Martín de Balmaseda, Decretos del rey don Fernando VII. Año sexto de su restitución al trono de las Españas. Se refieren todas las reales resoluciones gene- 
Esta situación se mantuvo hasta la desaparición del Santo Oficio en 1834. A partir de entonces encontramos otra vez hebreos de Gibraltar que vienen a España a convertirse: la primera de ellos fue Loy Laredo, hija de Abraham Laredo y de Reyna Hassan, que fue bautizada en la vecina población de San Roque en ese mismo año de 1834 después de haberse fugado de la plaza ${ }^{8}$; su conversión en la cristiana María de los Dolores Petra Francisca Laredo fue acogida con gran alegría en San Roque cuyos habitantes celebraron sonoras fiestas coronadas con un baile público en honor de la neófita ${ }^{9}$.

Sea por las razones que fuere, bien espirituales o bien económicas ${ }^{10}$, seguimos encontrando conversiones de hebreos gibraltareños en los lugares más dispares de la geografía española durante la primera mitad del siglo XIX: Abraham Benamor «convencido de la nulidad del judaísmo para dar al hombre la salvación» se bautiza en Madrid en $1850^{11}$; Jacob Aguado es bautizado en Murcia con el nombre de Manuel Mariano en marzo de $1851^{12}$; Maimón Haim Beneluz hace lo propio en Orihuela en abril de $1854{ }^{13}$ mientras que Jacob Cohen recibe el bautismo en agosto de 1858 en la cercana ciudad de Málaga ${ }^{14}$; por último, en 1861 Jacob

rales que se han expedido por los diferentes ministerios y consejos en todo el año de 1819. Tomo Sexto (Madrid: En la Imprenta Real, 1820) págs. 325-326.

8 APSMC, San Roque, Bautismos, Libro 21, fol. 67r.

9 Valverde, Carta histórica y situación geográfica de la Ciudad de San Roque, págs. 159-161.

10 Julio Caro Baroja, Los judios en la España Moderna y Contemporánea, pág. 164. Algo parecido ocurría en estos momentos con los judíos de Orán; véase para ello Juan Bautista ViLAR, «Los judíos de Argelia (1833-1900) a través de la documentación diplomática española», Miscelánea de estudios árabes y hebraicos 30 (1981) págs. 49-81.

${ }^{11}$ La Época, Año II, núm. 325, Madrid, 24 de marzo de 1850, pág. 4.

12 Fue bautizado por el propio obispo de Cartagena; ("España, bautismos, 15021940", database, FamilySearch (<https://familysearch.org/ark:/61903/1:1:FXBM-PP8>: 11 February 2018), Manuel Mariano Agustin Aquado, 12 May 1826; citing Gibraltar, reference item 2 p 256 rn 77; FHL microfilm 1,328,257. Hay una descripción de su bautismo en el diario La España, Año IV, núm. 819, Madrid, 15 de febrero de 1851, pág. 1.

13 La Esperanza, Año X, núm. 2.924, Madrid, 2 de mayo de 1854, pág. 3.

14 Este hebreo era hijo de Samuel Cohen y Sinafae, vecinos de la ciudad de Tetuán y fue bautizado como Jacobo Juan de la Santísima Trinidad en la iglesia del Rosario de la ciudad de Málaga; (“España, Provincia de Málaga, registros municipales, 1760-1956”, 
Benamor, hermano de Abraham, se bautiza en San Sebastián ${ }^{15}$. Ahora bien, ya no había necesidad de convertirse para volver a residir en España como prueba la existencia de la comunidad hebrea de La Línea.

\section{LOS INICIOS DE LA COMUNIDAD HEBREA}

Es a mediados del siglo XIX cuando encontramos las primeras alusiones a la existencia de algunos hebreos afincados en el pequeño pueblo de La Línea, una población que todavía en estos años dependía administrativamente de la ciudad de San Roque. Y es un viejo soldado aragonés en sus memorias quien nos informa de ello:

Propuse á una hebrea que vivía en un café de la Línea me recibiese en la habitación que dormía con su familia y siempre había luz. Idea irrealizable y desatinada. Me rogó por Dios que no la comprometiera. Salté desde el tejado al patio á las dos de la mañana y me encontré con un joven de la casa que me preguntó á dónde iba á tales horas. -En busca de aventuras -le contesté. -Yo, -añadió- tenía una cita con una de las sirvientas de la hebrea, y me he fastidiado; duerme con su señora. La pobre nos oyó hablar y temblaba. La pasión nos convierte en bestias. La hermosa judía no faltó al Decálogo ${ }^{16}$.

Este frustrado lance galante ocurrido en torno a 1851 nos sugiere que ya habría alguna que otra familia hebrea afincada en La Línea. Y, de hecho, si nos atenemos al padrón de vecindad realizado en La Línea en 1894, el hebreo Mordejay Albo declara llevar residiendo en la villa 38 años, lo que retrotraería su presencia en ella hasta 1856, año en el que ponemos principio a la comunidad hebrea de La Línea. Poco después, y de acuerdo con los censos gibraltareños de esa época, encontramos ya las primeras hebreas nacidas en La Línea: Mary Beriro parece haber

\footnotetext{
database with images, FamilySearch (<https://familysearch.org/ark:/61903/1:1:KN7CZDT>: 11 March 2018), Jacobo Juan José de la Santísima Trinidad Coen; citing Birth Registration, Málaga, Málaga, Spain, archivos municipales, Málaga (municipal archives, Málaga); FHL microfilm 2,014,241. La noticia aparece también en la Gaceta de Madrid, núm. 222, de 10/08/1858, pág. 2.

15 Gaceta de Madrid, núm. 356, de 22/12/1861, pág. 4.

16 Romualdo NoguÉs, «Aventuras y desventuras de un soldado viejo, natural de Borja» en La España moderna, Año VIII, núm. 88 (1896) pág. 72.
} 
nacido en 1857 según el apunte de su defunción en el Hospital Colonial de Gibraltar ${ }^{17}$ mientras que Gimol Cazes en el censo gibraltareño de 1891 declara tener en aquel momento 33 años ${ }^{18}$, lo que nos llevaría a establecer su nacimiento en torno a 1858. Estos datos nos indican que, probablemente, estos individuos serían parte de una de las primeras comunidades hebreas permanentes -si no la primera- en suelo peninsular español desde la ya lejana expulsión de 1492.

Así pues, podemos rastrear la presencia cierta, incluso antes de la independencia de La Línea como municipio en 1870, de un pequeño grupo de hebreos procedentes de las ciudades del norte de África -Mordejai Albo procedía de Tánger y los padres de Gimol Cazes, Joseph y Luna, de Tetuán- ya establecidos en ella. Probablemente todos ellos abandonaron las ciudades marroquíes debido a la mala situación en la que los judíos se encontraban en todo el norte de África y se establecieron en la villa a partir de la segunda mitad del siglo XIX. Esta situación, que se agravó posteriormente con el inicio de las hostilidades entre España y Marruecos durante la guerra hispano-marroquí de 1859, hizo que contingentes de refugiados de la judería de Tetuán fuesen acogidos en Gibraltar ${ }^{19}$, así como también en los presidios españoles del norte de África y varios puertos del sur peninsular donde permanecieron sin ser molestados hasta el final de la guerra hispanomarroquí; uno de esos puertos fue La Línea donde se asentaron algunos de ellos que fueron asistidos por el médico de origen húngaro Philiph

17 Según el censo de 1901, nació en La Línea en torno a 1861 (GNA, Census, $1^{\text {th }}$ Division, Gibraltar, 1901, fols. 47v-48r). Pero a su muerte en el año 1917 dice tener 60 años por lo que habría nacido en torno al año 1857; "Gibraltar Registry Births Marriages Deaths", database with images, FamilySearch $(<\mathrm{https}$ ://www.familysearch.org $>$ ) Mary Beriro 30 Oct 1917; citing Gibraltar Deaths FHL microfilme 008070620.

18 Aparece nombrada en este censo como Gimol Benatar ya que casó con Elías Benatar (GNA, Census 1891. 2nd Division, 1891, s.f.). Murió el 13 de enero de 1893 a los 37 años. Vuelve a aparecer como nacida en las Líneas Españolas en el apunte de su defunción en el Hospital Colonial de Gibraltar; "Gibraltar Registry Births Marriages Deaths", database with images, FamilySearch (<https://www.familysearch.org $>$ ) Gimol Benatar 13 Jan 1893; citing Gibraltar Deaths FHL microfilme 008070619.

19 Maximiliano de Austria describe cómo vivían estos hebreos en Gibraltar y en el istmo vecino; (Maximiliano I, Emperador de México, Recollections of my life, Vol. II (London: Richard Bentley, 1868) págs. 315-318. 
Hauser ${ }^{20}$. Quizá esta circunstancia hizo que la comunidad hebrea aumentara al comprobar que podían establecerse y vivir libremente sin ser molestados en La Línea y a su vez poder pasar a la colonia de Gibraltar donde la mayoría de ellos iba a trabajar diariamente.

A estos hebreos ya establecidos en La Línea se uniría un nuevo grupo procedente de Gibraltar que también se instaló en el nuevo municipio. Una vez desaparecida la prohibición de construir y reparar en la villa y liberada esta de la tutela del Ramo de Guerra ${ }^{21}$, vemos cómo varios vecinos de la inmediata plaza de Gibraltar comienzan a mercar terrenos en la Línea: Salomón David Garsón compra a Santiago Rissoto un pedazo de terreno de noventa y ocho varas situado en la calle Real del punto de la Línea en enero de $1870^{22}$; en febrero de 1874 Moisés Creciente y Auchel compra unos terrenos cercanos a la Atunara a Cristóbal Ramírez Gallardo ${ }^{23}$; David Mosés Benaim compra en mayo de 1874 un terreno en el camino a la Atunara 24; por último, Elías Sebag posee unos terrenos en la calle del Clavel lindando con los de su cuñado Salomón Sananes ${ }^{25}$ y a este se le da aviso para que ponga una

20 Jacobo IsRael Garzón, Los judios hispano-marroquíes (1492-1973) (Madrid: Hebraica Ediciones, 2008) pág. 138. Después de este episodio, Hauser se avecindó en Gibraltar junto con su mujer Pauline y allí nacieron sus tres hijos Alphonse, Henry y Lionel; véase GNA, Census, 1868 y GNA, Census, 1871.

${ }^{21}$ En 1862 se prohibió la construcción y reparación de edificios en la Línea y el Campamento y en enero de 1870 se levantó dicha prohibición; $c f$. José DE LA VEGA Rodríguez, La Linea de la Concepción. Cien años de historia 1870-1970 (Cádiz: Diputación Provincial, 1973) pág. 40.

22 En el terreno había un huerto cercado de cañas y pitas y en él una choza de juncos de dos habitaciones, un pozo y un juego de bolas; $c f$. AHPC, San Roque, Protocolo 271: Compraventa. Santiago Rissoto Ventura a favor de D. Salomón David Garsón. San Roque, 4 de enero de 1870, fols. 1v-8r.

${ }^{23}$ AHPC, San Roque, Protocolo 55: Venta. D. Cristóbal Ramírez a D. Moisés Creciente y Hachuel. San Roque, 19 de febrero de 1874, fols. 72r-76v.

24 AHPC, San Roque, Protocolo 55: Venta. D. Ysabel Moreno y Contreras a favor de D. David Mosés Benaim y Bitton. San Roque, 8 de mayo de 1874, fols. 255r-258v.

25 AHPC, San Roque, Protocolo 55: Venta. D. José Antonio Tortello y Mora representado por D. Ygnacio Franco y Silva a favor de D. Salomón Sananes y Sananes y D. Elías Sebag y Sabbah. San Roque, 14 de julio de 1874, fols. 476r-479v. 
empalizada en un terreno de su propiedad por cuestiones de orden público en $1876^{26}$

Todas estas noticias nos indican que hay un grupo de hebreos de Gibraltar con una voluntad clara de avecindarse en la nueva villa o bien de tener una segunda residencia en ella ya que, tras la compra de estos terrenos en la villa, estos nuevos propietarios comenzaron a levantar en ellos sus casas: en 1876 Judah Levy, vecino de la plaza de Gibraltar, solicita que se le señale las líneas donde debe construir su casa en un terreno de su propiedad en la prolongación de la calle del Clavel $^{27}$; a Salomón Conquy se le da alineación para edificar una casa en un terreno de su propiedad situado en el Huerto de la Canaria en ese mismo año ${ }^{28}$; Samuel Levy tiene una casa proyectada en la prolongación de la calle Barceló en un terreno comprado a don Juan y don Agustín Garesse ${ }^{29}$; Salomón David Garsón comienza a levantar una casa propia en $1875^{30}$ y en enero de 1876 paga 450 reales por el empedrado de la fachada de la casa que está construyendo en la calle Barceló ${ }^{31}$; por último, a Elías Sebag le sorprende la muerte en 1877

${ }^{26}$ AHMFT, Gobierno. Ayuntamiento. Libro de sesiones de la Corporación Municipal, 20 de mayo de 1876, fol. 71r.

27 AHMFT, Gobierno. Ayuntamiento. Libro de sesiones de la Corporación Municipal, 17 de agosto de 1876, fols. 127r-127v y AHMFT, Gobierno. Ayuntamiento. Libro de sesiones de la Corporación Municipal, 24 de agosto de 1876, fol. 131v. El terreno era un pedazo de huerto situado en la calle del Clavel (AHPC, San Roque, Protocolo 55: Venta. Ricardo Chichón y Herrera a favor de D. Judas Levy y Cohen. La Línea, 6 de agosto de 1874, fols. 542r-546v).

28 AHMFT, Gobierno. Ayuntamiento. Libro de sesiones de la Corporación Municipal, 22 de junio de 1876, fols. 91v-92r.

29 AHMFT, Gobierno. Ayuntamiento. Libro de sesiones de la Corporación Municipal, 21 de mayo de 1879, fols. 35r-36v.

30 AHMFT, Gobierno. Ayuntamiento. Libro de sesiones de la Corporación Municipal, 23 de diciembre de 1875, fol. 177r-v.

${ }^{31}$ En el terreno edificó «una casa de cuerpo bajo compuesta de sala, dos alcobas, dos cocinas, otro cuarto, patio pozo y lugar escusado». Debo este documento a la amabilidad de D. Alfonso Escuadra. El documento que detalla el pago pertenece a D. Santiago Quintana y fue reproducido por D. Luis Traverso en su blog $<$ https://lalineaenblancoynegro. blogspot.com>. 
cuando está edificando una casa en unos terrenos de su propiedad situados en la calle del Clavel ${ }^{32}$.

Así pues, confluirán en La Línea dos grupos de hebreos: los procedentes del norte de África, más pobres y sin excesivos recursos económicos, y los procedentes de Gibraltar, burgueses relativamente acomodados, que pueden permitirse tener una segunda residencia en la villa. Ambos grupos conformarán la comunidad hebrea de La Línea que iniciará en estos momentos su andadura en la ciudad, una andadura que alcanzará hasta el inicio de la Guerra Civil española en julio de 1936.

\subsection{Número y procedencia}

En el censo que se llevó a cabo en el año 1877 en toda la nación española aparece ya establecida en la entonces villa de La Línea una población hebrea que constaba de 68 individuos, distribuidos en 33 hombres y 35 mujeres ${ }^{33}$. Teniendo en cuenta que la población de la villa alcanzaba según ese mismo censo nacional la cifra de 9.155 habitantes, la comunidad judía suponía un escaso $0,75 \%$ de la población total ${ }^{34}$.

Tabla 1

Israelitas en el censo nacional de 1877

\begin{tabular}{|l|c|c|c|}
\hline & Hombres & Mujeres & Total \\
\hline Ceuta & 57 & 37 & 94 \\
\hline La Línea & 33 & 35 & 68 \\
\hline Melilla & 30 & 7 & 37 \\
\hline
\end{tabular}

32 AHPC, San Roque, Protocolo 65: Doña Raquel Sananes y Sananes de Sebag. Descripción de bienes por muerte de su marido Elías Sebag y Sabbah. San Roque, 18 de septiembre de 1877, fols. 1262r-1270v.

${ }^{33}$ No hemos podido acceder todavía a la lista de vecinos que fundan la villa en 1870 , lo que clarificaría el número y procedencia de estos hebreos que aparecen censados en 1877.

34 INE, Fondo documental. Censos de población. Siglo XIx. Censo de la población de España. 1877. Recuperado de <https://www.ine.es/inebaseweb/treeNavigation. do? $\mathrm{tn}=192225>$ [Consultado el 30 de julio de 2019]. 


\begin{tabular}{|l|c|c|c|}
\hline & Hombres & Mujeres & Total \\
\hline Algeciras & 5 & 5 & 10 \\
\hline Chafarinas & 1 & 1 & 2 \\
\hline
\end{tabular}

Fuente: INE. Censo nacional de población. 1877.

Ahora bien, teniendo en cuenta que el total de hebreos que había en España según el censo de población de 1877 ascendía a 406, los judíos que se habían establecido en La Línea representaban el 16,75\% del total de la población israelita en el país; y si a estos unimos los israelitas procedentes de Ceuta, Melilla, Chafarinas y la cercana ciudad de Algeciras, encontramos que todos ellos suman casi el 52\% de la población judía en España; así pues, en aquel momento más de la mitad de toda la población hebrea española se concentraba en el área del campo de Gibraltar y en las plazas de soberanía del norte de África.

Esta población hebrea siguió creciendo poco a poco en los años siguientes ${ }^{35}$. En primer lugar, por la dificultad de residir en Gibraltar donde había poco espacio disponible: la vivienda en la colonia era un bien escaso y caro y por ello muchos de sus vecinos más pudientes se trasladaban a residir a La Línea, aunque seguían manteniendo sus negocios en la plaza vecina; en segundo lugar, por las trabas que ponía el gobierno británico a que los trabajadores extranjeros se estableciesen en la propia ciudad de Gibraltar tal y como afirmaba certeramente el Ayuntamiento de San Roque al oponerse a la independencia administrativa de la Línea en 1870:

El aumento de la población en La Línea se debe a las restricciones del Gobierno inglés para residir en Gibraltar y por eso, portugueses, genoveses, judíos, otros extranjeros y muchos españoles, a quienes no se les permite pernoctar en el territorio inglés, viven en La Línea para poder entrar todos los días en aquella plaza ${ }^{36}$.

${ }^{35}$ Un testigo afirma que en La Línea hay «400 hebreos que tienen sus tenduchos en Gibraltar» pero su observación es seguramente exagerada (El siglo futuro, Año V, núm. 1.473, Madrid, 14 de octubre de 1880, pág. 2).

36 AMSR, Actas capitulares, 26 de marzo de 1870, citado por Juan Manuel BALLESTA Gómez, La verja de Gibraltar. Historia de una frontera (Castellarte S.L.: Castellar, 2005) pág. 183. 
Por estas razones algunos hebreos solicitaban al Ayuntamiento de la recién nacida villa que se les permitiese vivir y trabajar en La Línea y llevar su trabajo a la inmediata plaza de Gibraltar: así el hebreo Judas Dodo solicitó en agosto de 1870 que se le admitiese la residencia en la villa para poder dedicarse a su trabajo de hojalatero y poder exportar su trabajo a la colonia británica ${ }^{37}$. Esta situación se repetiría tercamente a lo largo de todo el período en el que la comunidad hebrea de la villa existió puesto que la decisión de las autoridades coloniales de impedir el asentamiento de extranjeros en la plaza se mantuvo firme hasta bien entrado el siglo $\mathrm{xx}$.

El segundo factor para la presencia de hebreos en la ciudad era la emigración de la población judía del norte de África ante la falta de perspectivas viables para sobrevivir en un entorno potencialmente hostil como era el imperio de Marruecos en aquellos días. La vida el norte de África, para los judíos, era cara y peligrosa y por ello buscaban emigrar a lugares cercanos como Ceuta, Orán, Melilla o la propia Línea donde el coste de la vida era mucho más asequible y en el caso de esta última, se añadía la posibilidad de trabajar en la colonia vecina donde había ya establecida una próspera comunidad judía ${ }^{38}$. Obviamente su principal objetivo era asentarse en Gibraltar, pero si se le impedía, se dirigían a La Línea. Así, en el mes de julio de 1883, las autoridades de la villa vieron cómo un número importante de hebreos desembarcaba en su territorio: tras la negativa de las autoridades británicas de Gibraltar a que entrasen en la plaza, el vapor que los transportaba desde el norte de África los desembarcó en La Línea. Esto obligó al comandante de la plaza y al alcalde de la villa a comunicarlo al gobierno de la nación y preguntar qué se hacía con estos judíos que presentaban «aspecto pobre y miserable» ${ }^{39}$. El gobierno ordenó al Ayuntamiento de la villa que dispusiera la expulsión inmediata de la población de estos hebreos procedentes de Marruecos, cosa que se ejecutó inmediatamente ${ }^{40}$.

37 AHMFT, Gobierno. Ayuntamiento. Libro de sesiones de la Corporación Municipal, 24 de agosto de 1870, s.f.

38 López Álvarez, «La comunidad judía de Tetuán», pág. 215.

39 El Globo, Año IX, núm. 2.831, Madrid, 25 de julio de 1883, pág. 3.

40 «Asimismo quedó enterado el Ayuntamiento de que en virtud de órdenes de la superioridad se había dispuesto la salida de la población de hebreos que se encontraba 
Sin embargo, a finales del siglo XIX la comunidad hebrea parece haber sufrido un ligero descenso ya que en el padrón realizado en el año 1894 solo encontramos avecindados en la villa de La Línea unos 43 hebreos distribuidos en 21 hombres y 22 mujeres. Es posible que la mencionada expulsión de 1883 hiciera que no quisieran censarse por precaución ya que por los libros de reemplazo del servicio militar sabemos que hay otras familias de hebreos en la villa en estos años: así de la lista de mozos de reemplazo entre 1913 y 1915 -los reemplazos correspondientes al tiempo del padrón de vecindad-podemos deducir que hay al menos otros catorce hebreos (cinco mozos nacidos ya en La Línea entre los años 1893 y 1895 junto con sus padres respectivos) que probablemente debían de vivir en aquellos momentos en la villa ${ }^{41}$. Por lo tanto, la comunidad estaría en torno a los 57 individuos en estos momentos.

Tabla 2

Padrón de vecindad de 1894

\begin{tabular}{|l|c|c|c|}
\hline \multicolumn{1}{|c|}{ Nombre } & Naturaleza & Oficio & Edad \\
\hline 1. Paulina Bensusan & Gibraltar & Su sexo & 23 \\
\hline 2. Enrique Rivera Bensusan & Línea & Su sexo & 3 \\
\hline 3. José Rivera Bensusan & Línea & Su sexo & 1 \\
\hline 4. Mordejay Albo & Tánger & Recovero & 42 \\
\hline 5. Mesoda Albo & Mogador & Su sexo & 20 \\
\hline 6. Samuel Cohen & Tánger & Jornalero & 53 \\
\hline 7. Sol Cohen & Tánger & Su sexo & 50 \\
\hline 8. Rajal Cohen & Tánger & Su sexo & 18 \\
\hline
\end{tabular}

en ella recién llegados de Marruecos» (AHMFT, Gobierno. Ayuntamiento. Libro de sesiones de la Corporación Municipal, 25 de julio de 1883, fol. 90r).

${ }^{41}$ Se trata de Mosés Laredo, Ester Sixu y José Laredo Sixu; Monfalem Benehi, Freja Serruya e Isaac Benehi Serruya; Abraham Barjayón, Jarifa Abecasis y Monjaluf Barjayón Abecasis; Jonás Benchimol y José Benchimol; Eliaj Busagla, Ragel Samitt y Mondejay Busagla Samitt (AHMFT, Servicios. Quintas. Libro que contiene los alistamientos formados por esta Corporación Municipal desde 1913, La Línea, 1913-1935, hh. 1-40). 


\begin{tabular}{|l|c|c|c|}
\hline \multicolumn{1}{|c|}{ Nombre } & Naturaleza & Oficio & Edad \\
\hline 9. Zahara Cohen & Línea & Su sexo & 14 \\
\hline 10. Ysaac i? & Tánger & Jornalero & 30 \\
\hline 11. Alegría Benarok & Tánger & Su sexo & 20 \\
\hline 12. Rodie ¿? Benarok & Tánger & Su sexo & 7 \\
\hline 13. Lirio ¿? Benarok & Tánger & Su sexo & 10 \\
\hline 14. Abraham ¿? Benarok & Tánger & Su sexo & 9 \\
\hline 15. María ¿? Benarok & Tánger & Su sexo & 6 \\
\hline 16. Jama ¿? Benarok & Tánger & Su sexo & 1 \\
\hline 17. Gertrudis Leví Elis & Gibraltar & Su sexo & 24 \\
\hline 18. Lucila Leví Elis & Gibraltar & Su sexo & 20 \\
\hline 19. Samuel Cohen Salomón & Tánger & Recovero & 29 \\
\hline 20. Abraham Cohen Jamila & Tánger & Recovero & 28 \\
\hline 21. Sara Gabay Cohen & Tánger & Su sexo & 36 \\
\hline 22. María Cohen & Tánger & Su sexo & 17 \\
\hline 23. Rafael Cohen & Línea & Su sexo & 15 \\
\hline 24. Daniel Cohen & Línea & Su sexo & 12 \\
\hline 25. Isaac Cohen & Línea & Su sexo & 10 \\
\hline 26. Jamila Cohen & Línea & Su sexo & 6 \\
\hline 27. Jacob Benasayag Cohen & Tánger & Jornalero & 34 \\
\hline 28. Jamila Aroba & Tánger & Su sexo & 32 \\
\hline 29. Mordejay Salama & Tetuán & Recovero & 20 \\
\hline 30. Rica Salama & Tánger & Su sexo & 20 \\
\hline 31. José Salama & Línea & Su sexo & 4 \\
\hline 32. Moisés Salama & Línea & Su sexo & 3 \\
\hline 33. Maimón Salama & Línea & Su sexo & 2 \\
\hline 34. Alejo Benjallón & Tánger & Jornalero & 50 \\
\hline 35. Rajael Benjallón & Tánger & Su sexo & 50 \\
\hline 36. Abraham Benjallón & Línea & Su sexo & 10 \\
\hline 37. Jauna Benjallón & Línea & Su sexo & 12 \\
\hline 38. Raquia Benjallón & Línea & Su sexo & 6 \\
\hline
\end{tabular}




\begin{tabular}{|l|c|c|c|}
\hline \multicolumn{1}{|c|}{ Nombre } & Naturaleza & Oficio & Edad \\
\hline 39. Ester Benjallón & Línea & $\mathrm{Su}$ sexo & 3 \\
\hline 40. Judad Bensadón & Tánger & Recovero & 41 \\
\hline 41. Mesoda Labian & Tánger & $\mathrm{Su}$ sexo & 55 \\
\hline 41. Tamo Maluma & Tánger & $\mathrm{Su}$ sexo & 50 \\
\hline 43. Lucia Maluma & Tánger & $\mathrm{Su}$ sexo & 18 \\
\hline
\end{tabular}

Fuente: AHMFT, Servicios. Población. Padrón de vecindad. Tomos I-II. La Línea, 1894, s.f.

No han sobrevivido los siguientes padrones de vecindad por lo que no podemos seguir la evolución exacta de la comunidad, pero hemos consultado los padrones de cédulas de contribuyentes supervivientes que nos dicen que en 1898 había 19 individuos de raza hebrea en la villa ${ }^{42}$, aunque como en este padrón solo se contabilizaban los mayores de 15 años y, como en el caso anterior, sabemos de varios mozos con sus familias entre los años 1897 y 1899, la comunidad debía de tener un número mayor de miembros que el reflejado por el padrón de cédulas. A estos 19 habría que sumar un número desconocido de hijos menores de quince años (quizá unos diez o doce) lo que nos daría unos 37 o 39 individuos en total, un número menor con respecto a los registrados en el padrón de vecindad de $1894^{43}$.

Tabla 3

Padrón de cédulas de 1898

\begin{tabular}{|l|c|c|c|}
\hline \multicolumn{1}{|c|}{ Nombre } & Naturaleza & Edad & Domicilio \\
\hline 1. Simón Cohen & Tánger & 50 & Bailén \\
\hline 2. Sol Cohen & Tánger & 50 & Bailén \\
\hline
\end{tabular}

42 AHPC, Hacienda, Caja 1430: Padrones. Cédulas personales. Padrón de los individuos sujetos al impuesto de cédulas personales, La Línea, 1898-1899.

${ }^{43}$ Se trata de Isaac Cohen, Simi Benjamín y José Cohen Benjamín; Isaac Nahón y Juan Nahón Álvarez; Jusefe Chouchon, ¿Anna? Amar e Isaac Chouchon Amar (AHMFT, Servicios. Quintas. Libro que contiene los alistamientos formados por esta Corporación Municipal desde 1913, La Línea, 1913-1935, h. 99v-102v). 


\begin{tabular}{|l|c|c|c|}
\hline \multicolumn{1}{|c|}{ Nombre } & Naturaleza & Edad & Domicilio \\
\hline 3. Jaim Sabo & Gibraltar & 30 & Bailén \\
\hline 4. Ynés Jabaches & Tetuán & 21 & Bailén \\
\hline 5. Jaime Benchimon & Tánger & 36 & Clavel \\
\hline 6. Paulina Bensusan & Gibraltar & 24 & Clavel \\
\hline 7. Abraham Cohen & Tánger & 38 & Clavel \\
\hline 8. Sara Cohen & Tánger & 28 & Clavel \\
\hline 9. Benajen Cohen & Tánger & 19 & Clavel \\
\hline 10. Ragel Cohen & Tánger & 16 & Clavel \\
\hline 11. Mondejay Albó & Tánger & 40 & San Pablo \\
\hline 12. Mesoda Albó & Tánger & 30 & San Pablo \\
\hline 13. Yudad Bensalud & Tánger & 43 & Teatro \\
\hline 14. Mesoda Yaval & Tánger & 41 & Teatro \\
\hline 15. Mordejai Salama & Tetuán & 40 & Teatro \\
\hline 16. Rica Bendalam & Tánger & 22 & Teatro \\
\hline 17. Sede Acrich & Tetuán & 34 & Teatro \\
\hline 18. Abraham Boruguel Coen & Tánger & 27 & Teatro \\
\hline 19. Simi Bensusan & Tánger & 25 & Teatro \\
\hline
\end{tabular}

Fuente: AHPC, Hacienda, Caja 1430: Padrones. Cédulas personales. Pueblo. Padrón de los individuos sujetos al impuesto de cédulas personales. La Línea, 1898-1899.

Lamentablemente a partir de aquí no tenemos datos fidedignos sobre el número de hebreos avecindados en la ciudad. Parece que, a partir de 1900, coincidiendo con un deterioro de la economía de los judíos gibraltareños, hubo un pequeño número de ellos que se afincó en La Línea huyendo de esta situación, pero a pesar de ello la comunidad hebrea fue disminuyendo durante el primer tercio del siglo xx hasta que terminó por reducirse a su mínima expresión en 1938 cuando se contaban solo cuatro hebreos adultos en la ciudad ${ }^{44}$. 1938 .

44 AHMFT, Servicios. Población. Padrón de cédulas personales, La Línea, circa 
¿De dónde procedían estos hebreos que se asientan en La Línea en el último cuarto del siglo xIx? En un principio podríamos pensar que la mayor parte de estos individuos establecidos en la Línea procedían de la cercana colonia de Gibraltar -y esto es así en alguna que otra ocasión-, pero en la mayoría de los casos que hemos podido documentar todos ellos procedían del norte de África; y en particular, provienen de la ciudad de Tánger, siendo testimoniales los hebreos procedentes de las ciudades de Tetuán y de Mogador.

Así, en el padrón de vecindad de 1894 , el $60 \%$ de los hebreos proceden de la ciudad de Tánger, el 30\% son ya nacidos en La Línea y el $10 \%$ restante se reparte entre Tetuán, Gibraltar y Mogador; y en el padrón de cédulas de 1898 la proporción es casi idéntica, aunque no podemos saber el porcentaje de nacidos en La Línea. Curiosamente es una composición totalmente opuesta a la comunidad de Sevilla en la que en estos años predomina la procedencia de la ciudad de Tetuán frente a unos pocos naturales de Tánger ${ }^{45}$. De esa ciudad tan cercana solo tenemos noticias de tres individuos: Mesod Pimienta ${ }^{46}$, Ynes Yabaches y Mordejay Salama. El hijo de este último, Salvador Salama, recuerda cómo su padre vivía en Tetuán a finales del siglo XIX y cómo desde allí emigró a La Línea:

Mi padre era de Tetuán, Marruecos (al Norte de África). Allí había muchos judíos: 7.000 u 8.000 aproximadamente. La zona donde estaban nuestras casas todos la llamábamos la judería y era como una especie de gueto, aunque no cerrado más bien era como el barrio judío de la ciudad. De allí mi padre se fue a La Línea con toda su familia, hace ya más de 73 años ${ }^{47}$.

45 «Todos los judíos que hay en Sevilla son de la costa de Marruecos, incluso un servidor de Vd. que soy de Mogador, otro que es de Rabat; 2 ó 3 de Tánger; y los demás todos de Tetuán», apud Ángel Pulido, Españoles sin patria y la raza sefardí (Madrid: Establecimiento Tipográfico de E. Teodoro, 1905) pág. 344.

46 Se menciona a este hebreo de Tetuán como estante en La Línea en Ana María López Álvarez, La comunidad judia de Tetuán (1881-1940). Onomástica y sociología en el libro de registro de circuncisiones del rabino Yishaq Bar Vidal Haserfaty (Madrid: Ministerio de Educación, Cultura y Deporte-Museo Sefardí, 2003) págs. 118-119.

47 Saada Bentolila, «La colectividad judía. Un aporte a la historia de San Luis» en Los inmigrantes en San Luis y su relación con los nativos: estudios monográficos, 
Por último, también hemos encontrado algún súbdito español del norte de África -con probable origen hebreo- avecindado en la villa: Antonio Cohen, natural también de la cercana Tánger, solicitó en septiembre de 1876 ser colocado en el padrón de vecinos de la villa, petición a la que el Ayuntamiento accedió ${ }^{48}$.

\subsection{Nacimientos, matrimonios y defunciones}

Una vez que se asentaron definitivamente en España, los hebreos comenzaron a inscribir sus nacimientos y defunciones en el Registro Civil como el resto de los ciudadanos; poco a poco fueron acostumbrándose a casarse también civilmente siguiendo las leyes de España. Puesto que no hemos podido acceder a dicho registro nos es imposible acercarnos a este asunto de una manera científica. Sin embargo, intentaremos dar una visión de conjunto con los pocos datos que poseemos.

En cuanto a los nacimientos, es difícil saber la evolución de la comunidad hebrea linense ya que no nos consta que fuera siempre práctica habitual su inscripción en el registro. A esto se añade la movilidad que hay entre ambos lados de la frontera y que dificulta la percepción de qué familias están realmente o no afincadas en La Línea. Así entre los años 1858 y 1870 encontramos a Joseph y Luna Cazes, naturales ambos de Tetuán, avecindados en La Línea donde nacen cuatro de sus cinco hijos: Gimol, Abraham, Isaac y Jacob y donde habrían permanecido al menos hasta ese año de 1870 ya que en el censo de 1871 están avecindados en la colonia vecina ${ }^{49}$; del mismo modo ocurre con la familia Acris: Abraham Acris e Ignacia Pérez, él natural de Gibraltar y ella de Algeciras, residen en La Línea entre 1874 y 1875 para pasar a continuación a la

coords. Marta I. López Lucero y Susana L. Domeniconi (San Luis: Editorial Universitaria San Luis, 1994) pág. 183.

48 AHMFT, Gobierno. Ayuntamiento. Libro de sesiones de la Corporación Municipal, 7 de septiembre de 1876, fol. 136v.

49 Su último vástago nace en Tánger en 1878 aunque puede ser que Luna Cazes se desplazara allí para tenerlo como hacían habitualmente algunas hebreas con posibles. Vuelven a aparecer en Gibraltar donde se establecieron permanentemente en torno a 1880: en el año 1881 ya aparecen censados en Morello's Ramp (GNA, Census, Gibraltar, 1881, s.f.). 
colonia británica en 1876: allí permanecen hasta 1878 en que vuelven a La Línea donde tienen dos hijos - Joseph y James- y residen en ella al menos hasta 1882, cuando tornan a volver a Gibraltar ${ }^{50}$.

La dificultad se hace mayor al comprobar que no sólo nacían en la villa los hijos de hebreos instalados en ella, sino que también venían a tener sus hijos los hebreos más pobres de Gibraltar. A partir de 1873 el gobierno de la colonia prohibió que las mujeres de los extranjeros tuviesen sus hijos en Gibraltar; esta prohibición, encaminada a no tener que conceder más nacionalidades de las deseadas por el gobierno de la colonia, obligó a muchas de las hebreas más pobres a dar a luz en $\mathrm{La}$ Línea mientras que las más pudientes se dirigían a Tánger ${ }^{51}$. Así encontramos casos como el de Coti Benatar, esposa de Haim Benzecry, que fue expulsada por el gobernador para que no tuviera su hijo en territorio británico y hubo de hacerlo en La Línea como también le ocurrió a Simi Levy o a Simi Masias durante estos años; aunque, en otros casos, es probable que lo hicieran voluntariamente como Donna Garsón, mujer de Salomón David Garsón, que poseía una casa en la calle Barceló desde 1875. Sin embargo, en 1885 se suavizó esta prohibición y se permitió que tuvieran sus hijos en territorio de la colonia, pero siempre con autorización expresa del gobernador ${ }^{52}$.

En cuanto a los matrimonios, nos encontramos con la misma situación de desconocimiento. Sí sabemos que cuando la situación económica se tornó difícil en la comunidad hebrea gibraltareña a principios del siglo xx, los más desfavorecidos que no tenían medios para buscar una esposa en Marruecos o en otras juderías europeas optaron por casarse

${ }^{50}$ En el año 1891 aparecen ya censados en Flat Bastion Road (GNA, Census, Book 1, Gibraltar, 1891, s.f.).

${ }^{51}$ El doctor Philliph Hauser, al que hemos visto auxiliando a los hebreos refugiados en Gibraltar y La Línea, tuvo un encontronazo con el gobernador precisamente por el nacimiento de su primer hijo en la colonia; $c f$. Pedro Bosch GIRAL et alii, Protagonistas de la química en España: Los orígenes de la catálisis (CSIC: Madrid, 2010) págs. 122-131.

52 Stacie BuRKe y Larry SAwCHUK, «Alien encounters: the ius soli and reproductive politics in the 19th-century fortress and colony of Gibraltar», History of the Family 6 (2001) págs. 531-536. 
con hebreas nacidas o residentes en La Línea ${ }^{53}$. Del mismo modo, comienzan a aparecer en estos momentos en la comunidad hebrea de Gibraltar algunos matrimonios mixtos entre judíos y gentiles: aunque no era una práctica muy común, a finales del siglo XIX, entre 1875 y 1889, encontramos cuatro matrimonios entre miembros de ambos colectivos y a partir de entonces la cifra crece poco a poco ${ }^{54}$.

La mayoría de estas mujeres fundamentalmente provenían de La Línea y de las poblaciones españolas más cercanas a la colonia británica ${ }^{55}$. Desconocemos si esto implicaba la conversión al judaísmo de la mujer: en algunas ocasiones -como en el caso de Angelines Morales casada con el linense Menahem Creciente- parece que ocurría así pero también conocemos uniones de hecho entre hebreos y cristianas -como sucede con Isaac Lasry y Juana Tocón- en el que cada cual perseveraba en su fe sin mayor problema ${ }^{56}$. En casos contrarios, como en el matrimonio de Biaggio D’Amato, industrial maltés afincado en La Línea, con la hebrea Lizzie Lengui, la situación era similar, siguiendo cada cual su credo.

Sí parece existir una ligera tendencia a que estas familias mixtas se establezcan en La Línea: entre 1894 y 1898 encontramos a Paulina Bensusan y su marido José Rivero avecindados en la ciudad ${ }^{57}$, o a los mencionados matrimonios entre Menahem y Angelines Creciente o Biaggio D’Amato y Lizzie Lengui durante la primera mitad del siglo xx. También otras familias mixtas se encuentran a caballo entre las dos ciudades: los hermanos James y Joseph Acris, ambos naturales de La Línea, se casan en Gibraltar por el rito católico ${ }^{58}$ y la familia Abecasis,

53 Lawrence A. Sawchuk y Doris Ann Herring, «Historic Marriage Patterns in the Sephardim of Gibraltar, 1704 to 1939», Jewish Social Studies 50:3-4 (1988) págs. 177 200 .

54 Lawrence A. SAwchuk y L. Waks, «Religious Exogamy and Gene Flow Among the Jews of Gibraltar, 1870-1969», Current Anthropology 24:5 (1983) págs. 661-662: 661 .

55 Sawchuk y Herring, «Historic Marriage Patterns in the Sephardim of Gibraltar», págs. 177-200.

56 Testimonio de doña Juana Lasry.

57 AMHFT, Servicios. Población. Padrón de vecindad. Tomo I. La Línea, 1894, s.f.

58 Joseph Acris se casa con la gibraltareña Florentina Bustos en agosto de 1898; ("Gibraltar Marriages, 1879-1918", database, FamilySearch (<https://familysearch.org/ ark:/61903/1:1:XT84-YSH>: 10 February 2018), Jose Acris and Florentina Bustos, 04 
de origen hebreo, pero bautizados como católicos, tiene negocios a ambos lados de la frontera e incluso uno de sus miembros, Alfred Abecasis, llega a fungir como espía español durante la guerra de Marruecos ${ }^{59}$.

Estas relaciones a veces creaban ciertas tensiones en la comunidad: la anteriormente mencionada Paulina Bensusan, hebrea natural de Gibraltar, huye de su casa en 1891 con el músico José Rivero -que le daba lecciones de guitarra- y se esconden en un convento de la policía española que la buscaba para devolverla a su casa; la reacción de la comunidad fue borrarla del libro de oraciones y se prohibió incluso hablar de ella ${ }^{60}$. Pero el caso más traumático de estas relaciones interraciales es el del pequeño Guillermo de Celis, un caso que tuvo cierta repercusión en la prensa española, que siguió de cerca los avatares del juicio celebrado en Tánger por la custodia del pequeño en marzo de $1888^{61}$. Abraham Attias, hebreo de Gibraltar, había seducido a una joven sirvienta llamada Catalina de Celis y había tenido con ella dos hijos. Después de un tiempo Abraham Attias marchó a América, abandonando a la sirvienta poco menos que en la miseria ${ }^{62}$. Un hermano de Abraham se ofreció a hacerse cargo de uno de

Jun 1898; citing St. Mary The Crowned, Gibraltar, reference; FHL microfilm 1,738,755; y James Acris con Salvadora Moreno, natural de la cercana población de Jimena en septiembre de 1899; ("Gibraltar Marriages, 1879-1918", database, FamilySearch (<https://familysearch.org/ark:/61903/1:1:XT8H-MQN>: 10 February 2018), James Acris and Salvadora Moreno, 16 Sep 1899; citing St. Mary The Crowned, Gibraltar, reference; FHL microfilm 1,738,755.

59 Julián Paniagua LóPEZ, «La red de servicios secretos españoles durante la guerra del Rif (1921-1927): los servicios especiales reservados dirigidos por Ricardo Ruiz Orsatti», Historia contemporánea 57 (2018) págs. 491-521: 504.

60 José María Abecassis, Genealogía hebraica. Portugal e Gibraltar. Sécs. XVII a XX. Vol. II: Beniso-Fresco (Lisboa: Sociedade Industrial Gráfica Telles da Silva, 1990) págs. 292-293.

${ }^{61}$ La historia apareció en varios periódicos nacionales como La Época (Año X, núm. 7.782, 7 de marzo de 1888) o Archivo diplomático y consular de España (Año IV, núm. 218, Madrid, 16 de mayo de 1888, págs. 138-139).

${ }^{62}$ Hay un Abraham Attias, natural de Gibraltar y nacido en torno a 1849, que emigró a Estados Unidos en 1875 y por la fecha podría corresponder con este individuo. Attias se naturalizó ciudadano estadounidense en el año 1894; ("United States Passport Applications, 1795-1925", database with images, FamilySearch $(<\mathrm{https} / / /$ familysearch. org/ark:/61903/1:1:Q24F-ZMQ3>: 16 March 2018), Abraham Attias, 1894; citing Passport Application, New York, United States, source certificate \#, Passport Applica- 
los niños, cosa a la que accedió la madre; pero este entregó el niño a su mujer Gimol quien lo llevó a Tánger donde lo crio. Recuperada la madre de su situación económica, quiso recobrar a su hijo, pero encontró que Gimol Attias no solo se negaba, sino que lo había convertido en hebreo, dándole un nuevo nombre - Rafael- $\mathrm{y}$ hasta circuncidándolo, a pesar de que había sido bautizado cristianamente en La Línea. El caso fue a juicio ya que la española pidió al consulado británico la devolución del muchacho, pero este le exigió una cantidad desmesurada para entablar la demanda. Ante la imposibilidad de afrontarlo, la española raptó al muchacho de la casa de su tía Gimol en Tánger y a su vez esta lo denunció ante el consulado de España. El asunto terminó en un juicio bronco celebrado en el consulado español de Tánger, juicio del que el cónsul británico se retiró alegando que no se estaba respetando el asunto fundamental, es decir, el rapto por parte de la madre española.

Por último, y en cuanto a las defunciones ocurridas en la comunidad hebrea de la ciudad, tenemos constancia de una treintena de ellas desde el último tercio del siglo XIx hasta el primer tercio del xx: una parte de ellos fue enterrado en el cementerio hebreo de La Línea donde en este período de tiempo encontramos una veintena de inhumaciones que comienzan con la de Benjamín Benislus en $1909^{63}$ y terminan con la de Estrella Setbon de Elmaleh en 1929 mientras que el resto de los fallecidos en la ciudad fue sepultado en la vecina plaza de Gibraltar; así ocurrió con Solomon Levy en el año 1876 ${ }^{64}$; Mesod Bensusan en 1902 y Haim Benatar en 1914 ${ }^{65}$; Rahma Levy ${ }^{66}$ y Mosés Laredo en $1915^{67}$;

tions, 1795-1905., 422, NARA microfilm publications M1490 and M1372 (Washington D.C.: National Archives and Records Administration, n.d.).

${ }^{63}$ Hay una tumba -que pudiera ser la primera inhumación- en la que se lee el año 1905 pero la inscripción está muy deteriorada. Para la tumba de don Benjamín Benislus, vid. ApÉNDiCe Fotográfico. Imagen 6, infra.

64 José María Abecassis, Genealogía hebraica. Portugal e Gibraltar. Sécs. XVII a XX. Vol. III: Gabay-Serfaty (Lisboa: Sociedade Industrial Gráfica Telles da Silva, 1991) pág. 332.

65 José María Abecassis, Genealogía hebraica. Portugal e Gibraltar. Sécs. XVII a XX. Vol. I: Abeasis-Benhayón (Lisboa: Sociedade Industrial Gráfica Telles da Silva, 1990) pág. 651.

\footnotetext{
66 AbeCAssis, Genealogía hebraica, vol. II, pág. 742.

67 Abecassis, Genealogía hebraica, vol. III, pág. 160.
} 
Mosés Acris en $1925^{68}$ y, por último, Sixto Abecasis González en $1926^{69}$.

\subsection{Profesiones}

A diferencia de otras comunidades hebreas próximas como las establecidas en las ciudades de Ceuta o Melilla, la comunidad linense no desempeña ninguna posición relevante en la vida económica o política de la ciudad: muy pocos de ellos aparecen dedicados al comercio y la industria y casi ninguno aparece entre los mayores contribuyentes de la villa; por el contrario, la mayoría de los hebreos que se establecen en la ciudad tienen un empleo de baja cualificación.

Esto es así sobre todo en el último cuarto del siglo XIX y principios del Xx. En estos años no hay entre los mayores contribuyentes de la villa ningún hebreo excepto Rafael Farache Zaragoza que aparece en la lista de 1884 pero en ese mismo año fue procesado por estafa y se dio a la fuga ${ }^{70}$. Del mismo modo hay muy pocos hebreos dedicados al comercio o la industria: Abram Nahón funge como comerciante al menos entre los años 1871 y $1872^{71}$ mientras que Salomón Sananes pone en marcha una fábrica de jabón en el año 187972; también sabemos que Abraham Acris estuvo inscrito en la matrícula del comercio e industria durante $1878^{73}$ o que el

68 ABECAssis, Genealogía hebraica, vol. I, pág. 252.

69 "Gibraltar Burials Records", database with images, FamilySearch $(<\mathrm{https}: / /$ www. familysearch.org>) item 1 1918-1930 Sixtus Abecasis 16 Jan 1926; citing St. Mary The Crowned, Gibraltar, reference; FHL microfilm 1738771.

70 BOP, núm. 67 de 21/03/1884, pág. 2 y BOP, núm. 135 de 13/06/1884, pág. 3.

${ }^{71}$ Surte al nuevo Ayuntamiento de libros en blanco encuadernados para llevar la contabilidad municipal (AHMFT, Hacienda. Intervención económica. Libro diario de caja. Contabilidad municipal, 1871-1872, fol. 2v). Vuelve a hacerlo al año siguiente (AHMFT, Hacienda. Intervención económica. Libro diario de caja. Contabilidad municipal, 1872-1873, fol. 4v).

72 AHMFT, Gobierno. Ayuntamiento. Libro de sesiones de la Corporación Municipal, 3 de septiembre de 1879, fol. 29r.

73 AHMFT, Gobierno. Ayuntamiento. Libro de sesiones de la Corporación Municipal, 18 de diciembre de 1878 , fol. $127 \mathrm{v}$. 
hebreo Mayer Beniscar también fungía como industrial en la villa en $1903^{74}$.

El resto de los hebreos, como refleja el padrón de vecindad de 1894, son fundamentalmente recoveros -que llevan huevos y gallinas de La Línea al mercado de Gibraltar para su venta- y jornaleros eventuales. Esto nos llevaría a pensar que era acertada la afirmación de José María Abecassis en su Genealogía hebraica cuando recoge la especie de que La Línea era el lugar «donde en aquel entonces vivían las familias más pobres y hasta indigentes» ${ }^{75}$.

A finales del siglo XIX y según el padrón de cédulas personales de 1898 la situación era prácticamente la misma ${ }^{76}$. Ahora bien, entrado el siglo $\mathrm{xx}$, constatamos que, al avecindarse algunos hebreos de la colonia británica en La Línea, su cualificación profesional es mayor: los hermanos Mesod y Mordejay Lengui son intérprete y comisionista respectivamente ${ }^{77}$; mientras que Sixto Abecasis González regenta una agencia de representaciones tanto en La Línea como en la vecina Gibraltar ${ }^{78}$; entre los hebreos naturales de La Línea, Isaac Laredo Sixu aparece como remachador ${ }^{79}$ aunque seguimos encontrando individuos con empleos de baja cualificación como José Cohen Benjamín y Rafael Gabay Levy que fungen como jornaleros ${ }^{80}$ o Salomón Cohen que tra-

${ }^{74}$ Gaceta de Madrid, núm. 89, de 30/03/1903, pág. 1.365.

75 Abecassis, Genealogía hebraica, vol. II, pág. 294.

76 AHPC, Hacienda, Caja 1430: Padrones. Cédulas personales. Pueblo. Padrón de los individuos sujetos al impuesto de cédulas personales. La Línea, 1898-1899.

77 «Mesod Lengui Beneluz, natural de Gibraltar, intérprete» y «Mordejay Lengui Beneluz, natural de Gibraltar, mecánico, residente en La Línea, calle del Clavel» (BOE, núm. 35, de 04/02/1942, pág. 720).

${ }^{78}$ La agencia estaba situada en la calle del Teatro de La Línea y en Parliament Lane en Gibraltar (El Financiero, Año XXI, núm. 1049, Madrid, 6 de mayo de 1921, pág. 1.019).

79 «Isaac Laredo Sigú, soltero, remachador con domicilio en La Línea, calle del Clavel» (BOE, núm. 35, de 04/02/1942, pág. 721).

${ }^{80}$ Vivía en la calle López de Ayala (AHMFT, Servicios. Población. Identidad local, 1931-1934, núm. 2984). Creemos que era hijo de Joseph Gabay y Mariam Levy y estaba casado con Masaltov Lengui, hermana de Mesod y Mordejay; $c f$. ABeCAssis, Genealogía hebraica, vol. III, pág. 209; vid. ApÉNDICE FOTOGRÁFICO. Imagen 2, infra. 
bajó como mayoral para las agencias de transporte La Veloz y El Águila ${ }^{81}$.

\subsection{La vida religiosa: la sinagoga y el cementerio}

La presencia de estas nuevas comunidades judías en un país como España donde no habían existido legalmente desde la expulsión de 1492 planteaba varios problemas ya que era una religión muy reglada y necesitaba de unas determinadas circunstancias para poder ser llevada a cabo con propiedad. Entre estos elementos necesarios para el desarrollo pleno de la vida (y de la muerte) judaica en la ciudad destacamos dos fundamentales: la sinagoga y el cementerio ${ }^{82}$.

\subsubsection{La sinagoga}

La proclamación de la libertad de culto durante la Revolución del año 1868 fue una de las novedades más interesantes de este acontecimiento histórico. A partir de entonces cualquier ciudadano podía practicar cualquier religión que no fuera la católica, lo que levantó una gran polémica en la nación durante todo el año 1869. Esto implicaba la erección de templos distintos a los católicos, algo que no se había visto en el país desde hacía siglos.

En un principio, cuando la comunidad se asentara en la villa linense y ante la inexistencia de templo, pasarían a practicar sus ritos a la vecina colonia de Gibraltar donde ya a principios del siglo XVIII, en 1724, había sido fundada por Isaac Netto la primera sinagoga de Gibraltar, la Shaar Hashamyim; junto con esta, podrían rezar en la Esnoga Chica, erigida en 1759, en la Esnoga Flamenca, establecida en 1799, o en otras dos

${ }^{81}$ Enrique Sánchez-Cabeza EARle, La Línea de mis recuerdos (La Línea: Copia mecanografiada, 1975) pág. 230.

82 Otras necesidades de su religión como la presencia de un mohel para las circuncisiones o la alimentación casher o incluso el propio rabino podían ser suplidas sin mucho problema por la comunidad vecina de Gibraltar. 
sinagogas ya del siglo xIx: la sinagoga Abudarham de $1820^{83}$ y otra, de la que no tenemos mucha más noticia, levantada por Joseph Bensusan en Punta Europa ${ }^{84}$.

Sin embargo, puesto que la pequeña comunidad estaba creciendo, necesitaba un templo para poder practicar debidamente los ritos de la religión hebrea y para ello necesitaban tener los elementos necesarios: así, en 1876 fueron llevados a La Línea los Rollos de la Ley de la antigua sinagoga gibraltareña de Punta Europa que había sido cerrada recientemente con lo que ya podían oficiarse las ceremonias judaicas con propiedad $^{85}$. Sus ritos se desarrollarían de forma muy parecida a la que Nogués describe para sus vecinos de Gibraltar:

En la Sinagoga el rabino, cubierta la cabeza con un manto blanco, desde la tribuna canta en hebreo y todos sin descubrirse responden balanceándose á compás. Las mujeres sólo van al templo en las grandes solemnidades y están separadas de los hombres ${ }^{86}$.

Ahora bien, no sabemos a dónde exactamente llevaron los Rollos de la Ley. Probablemente a una casa particular pero no tenemos ninguna certeza. Nuestra intuición nos lleva a pensar que la sinagoga estuvo, durante algunos años, en el actual número 5 de la calle del Teatro ${ }^{87}$. En primer lugar, por su extraña apariencia casi oriental que contrasta vivamente con las escasas viviendas burguesas del siglo XIX que han sobrevivido en la ciudad: es una casa de una sola planta que en su clave lleva inscrita el año 1881 -con las iniciales $A H$ de su primer propietario- y que presenta una fachada de estilo neomudéjar recorrida por una línea de mocárabes enmarcando las cuatro ventanas enrejadas que recuerdan vagamente por su aspecto a los mocárabes de la Sinagoga del Tránsito;

83 Tito BenADY, «The Jews of Gibraltar before the Treaty of Utrecht and the Development of the Jewish Community since», Cuadernos de Gibraltar 2 (2016-2017) págs. 43-66.

${ }^{84}$ Pulido, Españoles sin patria y la raza sefardí, pág. 349.

85 Esta sinagoga había sido construida por Joseph Levi Bensusan; $c f$. ABECAssis, Genealogía hebraica, vol. II, pág. 306.

${ }^{86}$ Nogués, «Aventuras y desventuras de un soldado viejo, natural de Borja», pág. 71.

87 Vid. ApÉNDICE FOTOGRÁFICO. Imagen 5, infra. 
la puerta de la vivienda está flanqueada por dos pilastras adosadas con un capitel de ataurique y enmarcada en un alfiz que enlaza con una decoración vegetal que sube hacia una cornisa que recorre la fachada de lado a lado decorada con pequeñas ménsulas de escayola.

Y, en segundo lugar, por la relación que se percibe entre la calle del Teatro y la comunidad judía. Aunque, como hemos visto anteriormente, los hebreos no se agrupaban en calles determinadas como en Sevilla, sí muestran cierta querencia por esta calle donde había varias familias hebreas avecindadas ya a finales del siglo $\mathrm{XIX}^{88}$. De hecho, cuando el Ayuntamiento de la ciudad, en agradecimiento por el papel jugado por el doctor Ángel Pulido en la construcción del nuevo cementerio ${ }^{89}$, le dio su nombre a una calle en 1902 escogió precisamente la calle del Teatro por tener en mente probablemente la actuación del doctor Pulido para con la comunidad sefardita.

Todo ello nos hizo pensar en esa posibilidad, aunque no podemos demostrarlo. Pero, si lo fue, solo fungió como sinagoga hasta los primeros años del siglo xx en que fue convertida en escuela.

\subsubsection{El cementerio}

Para las comunidades judías el cementerio responde a la necesidad de disponer de un lugar determinado en el cual los cuerpos de los difuntos puedan descansar. Para ellos esta necesidad era tan importante que a veces adquirían el espacio destinado a hacer la función de necrópolis antes que el de la propia sinagoga. En el caso de las nuevas comunidades que se asentaron en España, no fue hasta el último tercio del siglo XIX -momento en el que florecieron tímidamente las primeras comunidades españolas al calor de la libertad religiosa que irradiaba la

${ }^{88}$ En esa calle vivían o tenían propiedades algunos hebreos como David Mosés Benaim hasta 1880 (APHC, Hacienda, Caja 1370: Rectificación del amillaramiento para el expresado año económico. La Línea, 1881-1882, fols. 5v-6r), Judah Bensalón en 1894 (AHMFT, Servicios. Población. Padrón de vecindad, Tomo II, La Línea, 1894, s.f.) o los herederos de Mosés Salomón Serruya en 1923 (AHMFT, Hacienda. Tributaria. Registro de la propiedad urbana, Tomo 8. La Línea, 1923, s.f.).

89 De la Vega Rodríguez, La Línea de la Concepción, pág. 317. 
Constitución de 1869- cuando aparecieron las primeras necrópolis hebreas ${ }^{90}$.

La legislación emanada de esta carta magna estableció en 1871 que se reservase en los cementerios civiles una zona dentro de ellos para los que murieran fuera de la Iglesia católica ${ }^{91}$; y en 1872 se autorizó la construcción de cementerios profanos o civiles a los Ayuntamientos y a las sectas disidentes en lugar contiguo y separado del católico con cerca propia y acceso independiente:

La parte ampliada se rodeará de un muro ó cerca como lo demás del cementerio y el acceso á la misma se verificará por una puerta especial independiente de este, por la cual entrarán los cadáveres que allí deban inhumarse y las personas que los acompañen ${ }^{92}$.

Con lo que las bases legales para la existencia de cementerios hebreos en España estaban ya establecidas. Fue en las plazas norteafricanas de soberanía española donde surgieron las primeras necrópolis judías ya que allí arraigaron las primeras comunidades hebreas: así en 1873 la comunidad de Ceuta adquirió un terreno en las inmediaciones del cementerio católico de Santa Catalina donde levantó su cementerio; y en la ciudad de Melilla hicieron lo propio con el cementerio de la Alcazaba en el mismo año ${ }^{93}$.

90 Aunque ya la Ley de 29 de abril de 1855 autorizaba la creación de cementerios no católicos en España, el cementerio municipal aparece con el Decreto de 17 de noviembre de 1868 que autoriza la construcción del cementerio municipal de Madrid; $c f$. Marcelo Martínez Alcubilla, Diccionario de la administración española compilación de la novisima legislación de España peninsular y ultramarina, en todos los ramos de la administración pública, Tomo II (Madrid: J. López Camacho, Impresor, 1892) págs. 430 y 434.

91 Real Orden de 16 de julio de 1871; apud Martínez Alcubilla, Diccionario de la administración española, pág. 434.

92 Martínez Alcubilla, Diccionario de la administración española, pág. 436.

93 José Luis Gómez Barceló, «Lugares de enterramiento en la Ceuta de los siglos $\mathrm{XV}$ al XXI» en Cementerios, necrópolis y otros lugares de enterramiento de Ceuta, ed. José Luis Gómez BARCELó et alii (Ceuta: Consejería de Educación y Cultura, 2016) págs. 121-188. El primer enterramiento en el cementerio de Melilla es de 1883; $c f$. Jesús F. Salafranca Ortega, «Costumbres religiosas de los judíos melillenses», Aldaba 15 (1990) págs. 89-111: 107. 
En el caso de La Línea no fue hasta el año 1879 cuando la comunidad hebrea solicitó permiso para su propia necrópolis. Fue el vecino de la villa Judáh Medina quien se dirigió al Ayuntamiento en el mes de septiembre de ese año pidiendo que se les concediera un terreno para el descanso de sus difuntos:

[...] en atención al crecido número de hebreos que residen en esta localidad sería conveniente que el Ayuntamiento se dignara concederles y señalarles en sitio conveniente un pedazo de terreno donde pudieran construir un cementerio para enterrar á los que de su religión mueran en esta localidad ${ }^{94}$.

La comisión de ornato de la corporación emitió un informe sobre el expediente instruido a instancias de Judáh Medina y el Ayuntamiento acordó que cuando se señalase un nuevo lugar para la construcción se tendría en cuenta ${ }^{95}$. Del mismo modo que con los protestantes evangélicos -que precedieron a los hebreos en esta petición-, la corporación aprobó dicha petición y se llevó a cabo la acotación de un terreno junto al cementerio católico, donde, con la debida separación, se proyectó el cementerio judío ${ }^{96}$.

Sin embargo, el pueblo no acogió con demasiado agrado que se enterraran a evangélicos y a judíos junto a sus difuntos y se quejó, probablemente azuzado por el clero católico. Así que el Ayuntamiento de la villa tuvo que asegurarse de que se había separado de una manera estricta ${ }^{97}$ el cementerio católico de los cementerios de los que morían fuera del seno de la religión católica y en diciembre de 1883 se construyó una tapia junto al cementerio católico para separar a estos de los cadáveres

94 AHMFT, Gobierno. Ayuntamiento. Libro de sesiones de la Corporación Municipal, 3 de septiembre de 1879, fol. 26 r.

95 AHMFT, Gobierno. Ayuntamiento. Libro de sesiones de la Corporación Municipal, 19 de septiembre de 1879 , fol. 32 r.

96 De la Vega Rodríguez, La Línea de la Concepción, pág. 293.

97 «Los Ayuntamientos, y asociaciones religiosas disidentes que, contando con recursos, deseen construir cementerios especiales, podrán verificarlo, sujetándose á las disposiciones vigentes sobre higiene y policía sanitaria, previa la instrucción del oportuno expediente» (Real Orden de 2 de abril de 1883 en Gaceta de Madrid, núm. 93, de 03/04/1883, pág. 21). 
disidentes de dicha religión ${ }^{98}$; estas obras, según afirmaba un autor de la época, «han venido a acallar el clamor general y las quejas del vecindario» ${ }^{99}$.

Pronto se vio que el cementerio nuevo se había quedado pequeño debido al aumento espectacular que experimentó la población a finales del siglo XIX: el Ayuntamiento se vio obligado a buscar un nuevo emplazamiento, pero entre las múltiples tentativas y dilaciones en su construcción nunca olvidaron a los que no eran católicos: cuando en 1895 propusieron la compra de un terreno para el nuevo cementerio, especificaron que debía haber «al costado izquierdo otro pedazo unido al anterior de 10 metros de frente por 60 metros de fondo para enterramiento de aquellos que fallezcan fueran de la religión católica» ${ }^{100}$.

Por fin, en el año 1902 se comenzó la tan dilatada construcción de un nuevo cementerio y la necrópolis judía fue ubicada al este de la nueva construcción, aislada del resto de tumbas ${ }^{101}$. A partir de entonces el cementerio hebreo pudo empezar a desempeñar su función, siendo el primer enterramiento cierto que consta, el del hebreo Benjamín Benislus fallecido el 30 de agosto de 1909 como señalamos anteriormente ${ }^{102}$. A este siguieron dieciocho individuos (incluidos tres niños de muy corta edad que yacen en dos pequeñas tumbas) durante el período que estamos estudiando: la última inhumación es la de Estrella Setbon de Elmaleh que tuvo lugar en 1929.

98 AHMFT, Hacienda. Intervención económica. Libros de intervención, Año de 1883-1884, fol. 20r.

99 Lutgardo López Zaragoza, Gibraltar y su Campo. Guía del forastero (Cádiz: Establecimiento tipo-litográfico J. Benítez, 1899) pág. 113.

100 AHMFT, Gobierno. Ayuntamiento. Libro de sesiones de la Corporación Municipal, 11 de marzo de 1885, s.f.

101 Agradecemos a doña Hannah Benarroch que nos permitiera visitar el cementerio hebreo.

102 Vid. nota 63. 
Tabla 4

Inhumaciones en el cementerio de La Línea (1905-1929)

\begin{tabular}{|l|c|}
\hline \multicolumn{1}{|c|}{ Nombre } & Fecha \\
\hline 1. [ilegible] & ¿1905? \\
\hline 2. Benjamín Benislus & $30 / 08 / 1909$ \\
\hline 3. ¿Jebed Lahmi Maman? & 1909 \\
\hline 4. ¿Abraham? Serfaty & 1909 \\
\hline 5. Esther Beneluz & $30 / 04 / 1911$ \\
\hline 6. Niño sin nombre & 1911 \\
\hline 7. Niño sin nombre & 1911 \\
\hline 8. ¿..? Israel & $27 / 07 / 1912$ \\
\hline 9. Niño sin nombre & $13 / 12 / 1912$ \\
\hline 10. Josef M. Laredo & $21 / 12 / 1912$ \\
\hline 11. Salomón Ben Simeón & $14 / 06 / 1913$ \\
\hline 12. Judah M. Bensadon & $22 / 12 / 1915$ \\
\hline 13. Mesoda Albo & $30 / 04 / 1918$ \\
\hline 14. Judah Levy Cohen Fachena & $04 / 12 / 1918$ \\
\hline 15. Rica Salama & ilegible \\
\hline 16. José Salama Bendelach & $23 / 01 / 1920$ \\
\hline 17. Estrella Cohen & $30 / 04 / 1923$ \\
\hline 18. Freja Serruya & $19 / 07 / 1923$ \\
\hline 19. Estrella Setbon de Elmaleh & 1929 \\
\hline 20. Yamila Benasayag & Sin fecha \\
\hline
\end{tabular}

Fuente: Elaboración propia.

Es un número pequeño de enterramientos pero hay que tener en cuenta que en febrero de 1913 hubo un cambio sutil en la legislación española que permitió a los hebreos trasladar los cadáveres a Gibraltar sin muchos inconvenientes: el representante de la Gran Bretaña en Madrid presentó en ese año una petición para que el gobierno español permitiese por la frontera el paso de los cadáveres sin embalsamar de los súbditos británicos en las localidades cercanas como La Línea y el 
Campamento y este, oídos el gobernador militar del Campo de Gibraltar y el cónsul español en la colonia, promulgó un real decreto por el que permitía el paso de los cadáveres en las primeras veinticuatro horas siempre y cuando no hubiera ninguna enfermedad contagiosa y se solicitase permiso a la comandancia del campo de Gibraltar. Gracias a esta circunstancia los traslados de los difuntos judíos de la comunidad hebrea linense que fueran súbditos de la Gran Bretaña podían realizarse sin muchas trabas y el cementerio quedó probablemente como una segunda opción frente al de Gibraltar ${ }^{103}$.

Probablemente por esta causa no se le prestaba ninguna atención por parte del Ayuntamiento de tal modo que, en el año 1920, la comunidad judía de Tánger, a través de su Junta Representativa, recibió una petición de fondos para proporcionar las reparaciones requeridas por el lamentable estado en el que se encontraba ya el cementerio judío de La Línea ${ }^{104}$. Un testigo de la época nos confirma este mal estado de la necrópolis por estas fechas:

Como apenas era utilizado, el descuido en que se le tenía era evidente. Tuve oportunidad de apreciarlo en las dos ocasiones en que lo visité; ambas con ocasión del sepelio de miembros de una familia hebrea; doña Rica Bendalá de Salamá y su hijo don José Salamá Bendalá ${ }^{105}$.

El advenimiento de la República trajo algunas novedades en el ámbito legal de los cementerios: la ley de 30 de enero de 1932 convertía en civiles y municipales los cementerios y ordenaba derribar las tapias que separaban los cementerios civiles de los católicos ${ }^{106}$. Por lo que el Ayuntamiento de la ciudad derribó la tapia que separaba el cementerio civil del católico haciéndolo todo uno ${ }^{107}$. Esta situación perduró hasta diciembre de 1938 cuando esta ley fue derogada en plena guerra civil: además de ello, la nueva ley establecía que se devolviese a la Iglesia Católica la titularidad que le había arrebatado la República; y no solo

103 Gaceta de Madrid, núm. 53, de 22/02/1913, págs. 470-471.

${ }^{104}$ M. Mitchell Serels, A history of the Jews of Tangier in the nineteenth and twentieth centuries (New York: Sepher-Hermon Press, 1991) pág. 97.

105 Sánchez-Cabeza Earle, La Linea de mis recuerdos, pág. 71.

106 Gaceta de Madrid, núm. 37, de 06/02/1932, pág. 946.

107 Sánchez-Cabeza EARle, La Línea de mis recuerdos, pág. 71. 
eso, sino que establecía en su artículo segundo que las autoridades municipales restablecerían en dos meses «las antiguas tapias que siempre separaron los Cementerios civiles de los católicos» ${ }^{108}$.

La situación de la necrópolis permaneció inalterada hasta que, en marzo de 1958, José David Bentata, presidente del Comité del Cementerio Hebreo de Gibraltar, presentó una petición al Ayuntamiento de La Línea solicitando que le fuera concedida la propiedad de la parcela que ocupaba el viejo cementerio hebreo en el patio civil del cementerio municipal. Tras estudiar la petición, el Negociado de cementerios informó al Ayuntamiento que solo podía reconocerse la propiedad a favor de dicho Comité de una parcela de terreno de $45 \mathrm{~m}^{2}$ en el lugar solicitado por los hebreos de Gibraltar. Así pues, el Comité solicitó que le concedieran dichos $45 \mathrm{~m}^{2}$ y que además se les permitiera adquirir otros $39 \mathrm{~m}^{2}$ adicionales alrededor de la parcela ocupada por el viejo cementerio hebreo para su ampliación a lo que el Negociado dio su visto bueno siempre que el terreno resultante se vallara convenientemente. Por ello, el Ayuntamiento, con todos los informes favorables, reconoció a la Comunidad Hebrea de Gibraltar la posesión de la parcela del cementerio, autorizó la compra de los $39 \mathrm{~m}^{2}$ adicionales en forma de rectángulo de 7 metros por 12 metros de lado y, por último, dio permiso a José David Bentata para construir una muralla de cerco con puerta de hierro y apertura de hueco de puerta al exterior protegida por dicha puerta de hierro ${ }^{109}$.

Desde ese año de 1958 solo se han realizado ocho inhumaciones en el cementerio linense. Las últimas tuvieron lugar en los años 2007 y $2008^{110}$ y desde entonces no ha habido ninguna actividad en él, aunque

108 BOE, núm. 173 de 20/12/1938, págs. 3.039-3.040.

109 AHMFT, Gobierno. Ayuntamiento. Libro de sesiones de la Corporación Municipal, 28 de marzo de 1958, fols. 64r-65v; vid. ApÉNDICE FOTOGRÁFICO. Imagen 5, infra.

110 Según Jesús Majada Neila, en el año 1987, los judíos de Málaga dieron sepultura a doce cuerpos en el cementerio de La Línea cuando se cerró el viejo cementerio de San Rafael -donde los judíos tenían su propio terreno y donde eran enterrados sus difuntospor no tener una parcela específica en el nuevo cementerio de Parcemasa; $c f$. Jesús Majada Neila, Tras la estela de los judios en Málaga (Málaga: Diputación Provincial de Málaga, 1992) págs. 76-77. Pero en el cementerio de La Línea no hay rastro de estas inhumaciones. 
todavía sigue figurando como uno de los once cementerios judíos en activo que existen en la actualidad en España ${ }^{111}$.

\subsection{La vida cotidiana de la comunidad hebrea}

Los hebreos se integraron en la vida de la villa sin ningún problema. Al fin y al cabo, la población de La Línea era una población de aluvión compuesta por españoles, genoveses, malteses, portugueses y otros extranjeros por lo que la presencia de los hebreos no sería de las más extrañas. Esta diversidad de gentes fascinaba a Vicente Blasco Ibáñez que la describía de esta forma:

Algún día, en una novela, hablaré de La Línea: intentaré describirla en toda su complejidad interesante presentándola como la población más original de España. Es una ciudad de contrabandistas y fugitivos de todas las razas, mezclados con licenciados de presidio y criminales prófu$\operatorname{gos}^{112}$.

Sin embargo, la realidad era mucho más simple que la literatura. Las noticias que tenemos sobre nuestros hebreos nos los presentan viviendo pacíficamente confundidos en las mismas casas que el resto de la población, en los típicos patios que se levantaron en el último tercio del siglo XIX, y no agrupados en lugares determinados como los hebreos sevillanos que en estos mismos años se arracimaban en torno a las calles anejas a la Alameda de Hércules ${ }^{113}$. Así en la calle Cadalso existía un patio al que llamaban Patio de la Hebrea donde vivieron Judá Cohen Cohen y su esposa Masarto, matrimonio hebreo que había llegado a La Línea tras los sucesos de Casablanca del año 1907; en la misma calle, en el Patio del Águila, convivían carabineros de la Aduana y hebreos que se dedicaban a la recova en el mercado de Gibraltar como Judá

111 Los cementerios de la comunidad judía existentes en España en la actualidad pueden consultarse en <http://www.observatorioreligion.es/cementerios>.

112 Vicente Blasco IBÁÑEZ, Crónicas de viajes (Valencia: Ediciones Prometeo, 1967) págs. 46-47.

113 Los judíos sevillanos vivían agrupados en la calle Lumbreras y en la calle Feria; cf. Mario Méndez Bejarano, Histoire de la juiverie de Séville (Madrid: Editorial IberoAfricano-Americana, 1922) pág. 235. 
Cohen, hijo de los anteriores; por último, encontramos al hebreo natural de Mogador Judah Bensaguen Benthajau habitando en el Patio Negrotto, en la calle del Clavel o al tangerino Mesod Benjallón en el Patio del Inglés ${ }^{114}$. Otros hebreos vivían en otras calles del centro como la calle del Teatro, por la que parecen tener cierta querencia, o la contigua calle del Clavel donde hay hebreos instalados desde finales del siglo XIX. Y no solo se instalaron en el centro de la ciudad, sino que también los encontramos en la periferia, viviendo repartidos en otras zonas alejadas de la villa como las huertas del norte, lugar donde vivía Jacob Benasayag Cohen o incluso aún más apartados del centro de la villa como la barriada de la Atunara, junto a la mar de Levante, donde vivía Alejo Benjallón con su familia ${ }^{115}$.

Junto a estos hebreos más pobres también encontramos a otros con casa propia en la ciudad. En la rectificación del amillaramiento de 1880 aparecen David Mosés Benaim y Samuel Levy como propietarios que venden sus casas ${ }^{116}$; y poco después, en la rectificación de 1902, aparecen también con propiedades en la villa los hebreos Sultana Benamor, José Jaime Aboab y Solomón Moisés Jamila ${ }^{117}$. En 1911 encontramos a seis hebreos residentes en la ciudad con propiedades urbanas y también a doce hebreos gibraltareños con propiedades en la ciudad ${ }^{118}$; sin embargo, en el Registro de la propiedad realizado en la ciudad en 1923 ya solo aparecen tres hebreos con vivienda propia en la ciudad mientras que el resto de las propiedades pertenecen a miembros de la comunidad gibraltareña ${ }^{119}$.

114 Gaceta de Madrid, núm. 55, de 24/02/1891, pág. 596, y núm. 337, de 20/11/1900, pág. 875 .

115 AHMFT, Servicios. Población. Padrón de vecindad. Tomos I y II. La Línea, 1894, s.f.

116 APHC, Hacienda, Caja 1370: Rectificación del amillaramiento para el expresado año económico. La Línea, 1881-1882, fols. 5v-6r y 25v-26r.

117 AHMFT, Gobierno. Ayuntamiento. Libro de sesiones de la Corporación Municipal, 23 de mayo de 1902, fols. 63r-65v.

118 AHPC, Hacienda, Caja 1379: Repartimientos pueblos 1911. Repartimiento individual de la Contribución territorial sobre la riqueza urbana. La Línea, 1911, s.f.

119 AHMFT, Hacienda. Tributaria. Registro de la propiedad urbana, Tomos 1-27. La Línea, 1923. 
Tabla 5

Propiedades urbanas de los hebreos en La Línea (1911).

\begin{tabular}{|c|c|c|}
\hline Propietarios & Residencia & Propiedad \\
\hline Abraham Acris Benabú & La Línea & San Pedro Alcántara \\
\hline Jaime Aboab y otros & La Línea & Pedreras \\
\hline Sultana Benamor Attias & La Línea & Atunara \\
\hline Samuel Benaros Pariente & La Línea & Atunara \\
\hline Abraham Benelú Benabú & La Línea & Atunara \\
\hline Abraham Levy Bensalama & La Línea & Zabal \\
\hline Abraham Levy Bensirat & La Línea & Zabal \\
\hline Salomón Levy Valensi Benoliel & La Línea & Zabal \\
\hline Ana Martín Levy & La Línea & Príncipe de Asturias \\
\hline Enrique Levy Walpoly & Gibraltar & ---- \\
\hline Judas Levy Valensi & Gibraltar & $\begin{array}{ll}--- \\
--\end{array}$ \\
\hline J. Levy Abraham & Gibraltar & ---- \\
\hline Salomón Mosés Serrulla & Gibraltar & ---- \\
\hline Samuel Conqui Bensusan & Gibraltar & $\begin{array}{ll}--- \\
--\end{array}$ \\
\hline David J. Cazes & Gibraltar & ---- \\
\hline Aarón Cazes Benasuli & Gibraltar & 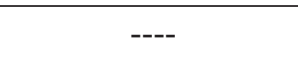 \\
\hline Ysmael David Salomón y otros & Gibraltar & $\begin{array}{ll}--- \\
--\end{array}$ \\
\hline David Mosés Benalú & Gibraltar & ---- \\
\hline Abraham Serfaty & Gibraltar & ---- \\
\hline Samuel Benchimol & Gibraltar & --- \\
\hline Levy Benatar Cubi & Gibraltar & $\begin{array}{ll}--- \\
--\end{array}$ \\
\hline Jacobo Benhayón & Gibraltar & $\begin{array}{ll}--- \\
---\end{array}$ \\
\hline David Bensusan Abraham & Gibraltar & --- \\
\hline José Levy ¿Lial? & Gibraltar & ---- \\
\hline
\end{tabular}

Fuente: AHPC, Hacienda, Caja 1379: Repartimientos pueblos 1911.

Repartimiento individual de la Contribución territorial sobre la riqueza urbana. La Línea, 1911, s.f. 
Tabla 6

\section{Propiedades urbanas de los hebreos en La Línea} y San Roque (1923)

\begin{tabular}{|l|l|c|c|}
\hline \multicolumn{1}{|c|}{ Propietarios } & Residencia & Propiedad & Localidad \\
\hline $\begin{array}{l}\text { Herederos de Salomón M. } \\
\text { Serruya }\end{array}$ & Gibraltar & General Muñoz Cobos s/n & La Línea \\
\hline Samuel Benchimol & Gibraltar & Granada, 131 & La Línea \\
\hline David Bendimón Benabú & Gibraltar & Carretera de España, s/n & La Línea \\
\hline Abraham Acris Benabú & La Línea & Colón, 64 & La Línea \\
\hline Samuel Benchimol & Gibraltar & Cádiz, 256 & La Línea \\
\hline Samuel Benchimol & Gibraltar & Cádiz, 254 & La Línea \\
\hline Joseph J. Acris & Gibraltar & San Bernardo & La Línea \\
\hline Sasón Benhayón de Belisho & Gibraltar & Paz, 38 & La Línea \\
\hline Boning Holechmel Masias & La Línea & La Colonia & La Línea \\
\hline $\begin{array}{l}\text { Herederos de Salomón M. } \\
\text { Serruya }\end{array}$ & Gibraltar & Dr. Ángel Pulido s/n & La Línea \\
\hline Solomón Benmijarg Velasco & La Línea & Emilio Castelar, 38 & La Línea \\
\hline Samuel Benchimol & Gibraltar & Antonio Maura, 80-90 & La Línea \\
\hline Samuel Benchimol & Gibraltar & Reina Cristina, 43-45 & La Línea \\
\hline Samuel Benchimol & Gibraltar & Huerta Norte derecha & La Línea \\
\hline León Ysrael & Gibraltar & Marqués de Estella, s/n & La Línea \\
\hline $\begin{array}{l}\text { Salomón L. Valency y } \\
\text { Benoliel }\end{array}$ & Gibraltar & Ramón Carranza s/n & La Línea \\
\hline Benedetto Salomón Benoliel & Gibraltar & - & San Roque \\
\hline David Benaim & Gibraltar & Gibraltar & San Roque \\
\hline Mesod Benady & & San Roque \\
\hline
\end{tabular}

Fuente: AMSR, Caja 2890, Leg. 1: Expediente de copia repartimiento de la contribución territorial por urbana, San Roque, 1923-1924 y AHMFT, Hacienda. Tributaria. Registro de la propiedad urbana, Tomos 1-27, La Línea, 1923.

120 Según nos informa don Tito Benady esta propiedad era la casa de la familia Cresswell que fue adquirida por su abuelo don Mesod Benady alrededor del año 1912, poco después de que doña Margaret Cresswell se jubilara como directora de la oficina de correos de Gibraltar. 
Entre una población tan variopinta como la que componía La Línea a finales del siglo XIX las costumbres de estos nuevos vecinos no debían de llamar mucho la atención. Pronto se adaptaron a las costumbres más visibles de la vecindad adoptando la forma de vestir de los restantes ciudadanos como hacían ya en el norte de África ${ }^{121}$ : al principio parte de ellos siguió fiel a la usanza africana -de hecho, un testigo español confunde a los recoveros judíos de la plaza de abastos de la ciudad con moros por su parecida vestimenta ${ }^{122}$ - pero pronto encontramos ya a hebreos vestidos a la europea como Judad Bensaguen que «vestía pantalón, chaqueta y chaleco de paño negro, camisa blanca, zapatillas blancas, y sombrero de hongo negro» ${ }^{123}$.

Pero esta lenta adaptación al medio no les hacía abandonar sus propias costumbres: Nogués nos dibuja un pequeño esbozo de los usos de los hebreos gibraltareños a mediados del siglo XIX, costumbres que no debían de ser muy diferentes de las usadas por los hebreos de La Línea:

Los judíos beben el vino que ellos fabrican, y queda impuro si algún cristiano toca las vasijas que lo contienen. [...] El rabino sacrifica los animales. No comen cerdo, conejo, liebre, pescado sin escamas ni duermen con su mujer en cierta época. El viernes guisan para el sábado la adafina. La de los ricos se compone de patatas, garbanzos, membrillos, huevos duros, patas de vaca, carne y arroz. La conservan veinticuatro horas caliente. El sábado no encienden luz ni reciben dinero. [...]. Creen que el ángel malo, al cortar el hilo de la vida, limpia la espada y se lava las manos en el agua que encuentra más cerca del judío que acaba de expirar y la vierten. Celebran varias Pascuas; ayunan sin comer ni beber en todo el día ${ }^{124}$.

Esta vida normal se vio alterada en pocas ocasiones. Escasean las noticias sobre incidentes en los que los hebreos se vean involucrados: solo encontramos alguna pelea que pudiera tener tintes antisemitas como

121 Para la vestimenta de los sefarditas en el norte de África, véase José Manuel Fraile Gil, «La indumentaria sefardí en el Norte de Marruecos. El tocado y la ropa de cada día», Revista de Dialectología y Tradiciones Populares LIX:2 (2004) págs. 43-92.

122 El siglo futuro, Año V, núm. 1.473, Madrid, 14 de octubre de 1880, pág. 2.

123 Gaceta de Madrid, núm. 55, de 24/02/1891, pág. 596.

124 NoguÉs, «Aventuras y desventuras de un soldado viejo, natural de Borja», págs. $70-71$. 
las lesiones recibidas por el hebreo Rubin Simoni en la taberna de la calle del Horno en $1896^{125}$ o algún robo como el hurto de unos anillos de oro sufrido por Moisés Aninacat en $1893^{126}$. También hay pocas noticias sobre incidentes entre la propia comunidad: destacamos el más grave de ellos, la violación de la hebrea Ragel Colum a manos de Samuel Farada en casa de Zahara Cohen en octubre de 1899 ${ }^{127}$; y el intento de asesinato de uno de los hebreos de la ciudad por sus congéneres del que no hemos encontrado nada excepto la reseña periodística:

El jueves pasado por la tarde, tres hebreas intentaron degollar en la Línea de la Concepción á un hebreo, el que se encuentra, según se dice, muy mal herido. Las agresoras fueron arrestadas ${ }^{128}$.

El resto son peleas triviales como las lesiones ocasionadas por Judá Bensaquen a Frajacinta Judad en $1890^{129}$ o las lesiones inferidas en una riña al niño Samuel Levi por Samuel Benjarro en marzo de $1882^{130}$. En cuanto al delito más común y característico de la zona, el contrabando, no hallamos nada excepto a la familia Abecasis enfangada en contrabando de armas: Mosés Abecasis alias el Morito y Samuel Berchimol son reclamados por la justicia española en relación con «cien kilogramos de pólvora y una caja de cápsulas metálicas para fusil Remington» que querían pasar a África desde el puerto de Algeciras en $1897^{131}$; poco después su hijo Sixto Abecasis González también es reclamado por el juzgado militar de Algeciras en abril de 1900 por conducir fraudulentamente a la plaza de Gibraltar «21 paquetes de cartuchos, sistema Remington, en la noche del 10 de junio de 1898 » en compañía de otro vecino de Gibraltar ${ }^{132}$.

125 Gaceta de Madrid, núm. 214, de 01/08/1896, pág. 431.

126 Gaceta de Madrid, núm. 73, de 14/03/1893, pág. 890.

127 Gaceta de Madrid, núm. 306, de 02/11/1899, pág. 422. Creemos que el nombre en realidad sería Ragel Cohen, hija de Abraham y Sara Cohen, que tendría 15 años en aquel momento (AHPC, Hacienda, Caja 1430: Padrones. Cédulas personales. Pueblo. Padrón de los individuos sujetos al impuesto de cédulas personales. La Línea, 1898-1899).

128 El pabellón nacional, Año XV, núm. 6544, Madrid, 10 de abril de 1884, pág. 3.

129 Gaceta de Madrid, núm. 328, de 24/11/1890, pág. 643.

130 Gaceta de Madrid, núm. 114, de 24/04/1882, pág. 271.

131 Gaceta de Madrid, núm. 68, de 9/03/1897, pág. 1.041.

132 Gaceta de Madrid, núm. 144, de 24/05/1900, pág. 924. 
Por lo demás, la vida de los hebreos en la ciudad transcurría sin muchos sobresaltos. Tan solo los violentos sucesos ocurridos en Casablanca en 1907 perturbaron la tranquilidad de la comunidad hebrea. Tras la intervención franco-española para sofocar los disturbios en la ciudad marroquí ${ }^{133}$, una parte de la población judía de Casablanca, asustada por la amenaza permanente de incursiones del bandido El Raisuli, huyó a Tánger y, en menor medida, a Gibraltar y las ciudades del sur de la península como ya había ocurrido en 1859 y $1860^{134}$. Sin embargo, el gobernador de la colonia británica se negó esta vez a recibirlos y los refugiados tuvieron que desembarcar en La Línea y Algeciras, ciudades que, a diferencia de los británicos, abrieron sus puertas con generosidad a la colonia hebrea ${ }^{135}$. Tras su cálida acogida por parte de los españoles, los refugiados en estas ciudades enviaron una carta de agradecimiento a Madrid que fue publicada en la prensa nacional y que, en nombre de los hebreos refugiados en La Línea, firmaron Samuel S. Abecasis y Samuel Attias ${ }^{136}$. A finales de agosto de 1907, Joseph Solomon Rahon, segundo intérprete del Consulado de España en la ciudad norteafricana de Mazagán, volvía a agradecer la acogida a España y se expresaba en estos términos elogiosos sobre la actitud que habían tenido no solo el pueblo sino también las autoridades de la villa linense:

[...] por último, demostrar su profundo reconocimiento a las autoridades, funcionarios públicos y honrado vecindario de esta villa de la Línea de la Concepción, en la que han fijado su residencia provisional donde han encontrado toda suerte de facilidades y donde están siendo objeto de las mayores atenciones, recibiendo a diario múltiples pruebas

${ }^{133}$ Hermenegildo Franco, «La marina española en los sucesos de Casablanca de agosto de 1907», Revista General de Marina 218 (1990) págs. 33-48.

134 «El comandante general del campo de Gibraltar telegrafía que, tanto en Algeciras como en la Línea de la Concepción y otros pueblos de aquel campo, se han refugiado numerosas familias hebreas, procedentes de Marruecos» (El Correo Español, Año XX, núm. 5.619, Madrid, 31 de agosto de 1907, pág. 2).

135 Robert Assaraf, Une certaine histoire des juifs du Maroc: 1860-1999 (Paris: Gawsewitch, 2005) pág. 140.

${ }^{136}$ La carta iba firmada en nombre del resto de la colonia que residía en Algeciras por A. A. Perl y por la comunidad israelita de Gibraltar, Salomón S. Benoliel. Apareció en varios diarios nacionales como $A B C$ (núm. 807, Madrid, 9 de septiembre de 1907, pág. 3) o El País (Año XXI, núm. 7341, Madrid, 10 de septiembre de 1907, pág. 2). 
de cariño y de consideración. Así para el digno señor comandante militar, D. César Aguado, como para los Señores administrador, interventor y vistas de la Aduana, funcionarios de Telégrafos y Correos, teniente de la Guardia civil, Capitán y oficiales de carabineros, inspectores de Orden público, sin olvidar al alcalde de la población, D. José Cayetano Ramírez, y á los jefes de la Guardia municipal, Sres. Guerrero y Veret, no tiene la colonia hebrea más que frases de elogio, y ella, que fué siempre la primera víctima en todas las contiendas de Marruecos no olvidará nunca la franca y generosa hospitalidad que está recibiendo en esta noble España de sus recuerdos ${ }^{137}$.

Sin embargo, a pesar de esta buena disposición hacia España en general, su relación con el Estado todavía era ambigua. Aunque, como el resto de los hebreos españoles, aceptaban poco a poco inscribir sus hijos o sus matrimonios en el Registro Civil de la nación, otras obligaciones que les tocaban como ciudadanos españoles les resultaban ajenas y las rehuían de plano: en los reemplazos para el servicio militar del último cuarto del siglo XIX y primer tercio del siglo XX aparece registrada casi una setentena de mozos de indudable prosapia hebrea y la mayoría de ellos no se presentan al llamamiento y son dados por prófugos durante los siguientes años ${ }^{138}$. Salvador Salama, un hebreo linense que terminó emigrando a la Argentina, recuerda bien por qué los judíos evitaban el servicio militar en España:

Mi hermano Moisés, lo mismo que mi hermano Alberto, vinieron porque tenían que hacer el Servicio militar. [...] Allí el servicio duraba tres años y cuatro en la marina. Pero para los judíos era terrible hacerlo, porque los mandaban deliberadamente a las zonas más peligrosas, en nuestro caso a las zonas de conflicto con los árabes y además los sometían a todo tipo de humillaciones y degradaciones. Así que escapar del servicio en esa época era más o menos tratar de preservar la vida ${ }^{139}$.

137 Las dominicales, Año VIII, núm. 342, Madrid, 8 de septiembre de 1907, pág. 4.

138 AHMFT, Servicios. Quintas. Libro que contiene los alistamientos formados por esta Corporación Municipal desde 1913, La Línea, 1913-1935, 497 h. y AHMFT, Servicios. Quintas. Libro que contiene los alistamientos formados por esta Corporación Municipal desde 1936, La Línea, 1936-1965, 493 h.

139 Bentolila, «La colectividad judía», pág. 183. 
Ante esto, el Ayuntamiento se limitaba a abrir expediente y como mucho a publicar en la Gaceta los nombres de los prófugos ya que poco más podía hacer en aquellos tiempos ${ }^{140}$. Todavía en una fecha no tan lejana como 1954, el Estado español reclamaba sin éxito a Manuel Lengui -hijo de Mesod Lengui, un masón gibraltareño avecindado en la ciudad- como prófugo por no haber acudido a la llamada a filas ${ }^{141}$. El caso es que solo algunos de los hebreos cumplieron con su deber, y de ellos la mayoría eran hijos de matrimonios mixtos, como los hermanos Sananes que fueron aptos para el servicio o como Juan Nahón que fue declarado apto para el servicio, pero solo como soldado auxiliar ${ }^{142}$.

Tabla $7^{143144145}$

Mozos llamados a filas (Reemplazos 1894-1955)

\begin{tabular}{|l|c|c|c|}
\hline \multicolumn{1}{|c|}{ Nombre } & Reemplazo & $\begin{array}{c}\text { Fecha } \\
\text { nacimiento }\end{array}$ & Situación \\
\hline Sebastián Attias Celis & 1894 & $23 / 10 / 1875$ & Útil \\
\hline Aurelio Martínez Sananes & 1899 & $15 / 03 / 1880$ & Prófugo $^{143}$ \\
\hline Abraham Biddau Coen & 1901 & c. 1881 & Prófugo $^{-18}$ \\
\hline Samuel Azedo Arroba & 1901 & c. 1881 & Prófugo \\
\hline Shimol Pinto Albo & 1901 & c. 1881 & Prófugo \\
\hline Abraham Bensaquén Más & 1902 & $26 / 01 / 1882$ & Prófugo \\
\hline José Tapiero Benchitrite & 1902 & $07 / 04 / 1882$ & Prófugo \\
\hline Jamira Melú Benchú & 1902 & $07 / 04 / 1882$ & Prófugo \\
\hline Josué Pinto Cohen & 1902 & $18 / 09 / 1882$ & Prófugo \\
\hline Salomón Azulauz Cohen & 1902 & $26 / 05 / 1882$ & Prófugo \\
\hline Ysaac Belbaroc Balsisou & 1904 & c. 1883 & Prófugo \\
\hline
\end{tabular}

140 Gaceta de Madrid, núm. 38, de 7/02/1904, págs. 538-539, y núm. 34, de 24/01/1908, págs. 329-330.

141 BOE, núm. 2 de 02/01/1956, pág. 32.

142 AHMFT, Servicios. Quintas. Libro que contiene los alistamientos formados por esta Corporación Municipal desde 1913, La Línea, 1913-1935, hh. 152v, 405v y 425v.

143 Estaba ausente en una república sudamericana en el momento del llamamiento a filas. 


\begin{tabular}{|l|c|c|c|}
\hline \multicolumn{1}{|c|}{ Nombre } & Reemplazo & $\begin{array}{c}\text { Fecha } \\
\text { nacimiento }\end{array}$ & Situación \\
\hline Daniel Cohen Gamba & 1904 & c. 1883 & Prófugo \\
\hline Joen Esacril Azulay & 1904 & c. 1883 & Prófugo \\
\hline Moisés Cohen Cuannon & 1904 & c. 1883 & Prófugo \\
\hline Jacob Benharok Bartolet & 1908 & c. 1887 & Prófugo \\
\hline José Ansaldo Abujaram & 1908 & c. 1887 & Prófugo \\
\hline Samuel Bedayan Cohen & 1908 & c. 1887 & Prófugo \\
\hline Isaac Benelú Serruya & 1908 & c. 1887 & Prófugo \\
\hline José Laredo Sixu & 1913 & $30 / 08 / 1892$ & Prófugo \\
\hline Isaac Benehi Serruya & 1913 & $17 / 06 / 1892$ & Prófugo \\
\hline José Zalama Bendenlach & 1913 & $31 / 01 / 1892$ & Prófugo \\
\hline Mosés Zalama Bendenlesch & 1914 & $18 / 04 / 1893$ & Prófugo \\
\hline Monjaluf Barjayón Abecasis & 1914 & $20 / 07 / 1893$ & Prófugo \\
\hline José Benchimol & 1915 & $24 / 06 / 1894$ & Inútil \\
\hline Mondejay Busagla Samitt & 1915 & $11 / 02 / 1894$ & Inútil \\
\hline Abraham Salama Bendenland & 1916 & $17 / 10 / 1895$ & Prófugo \\
\hline Maimón Benjallon Anzulay & 1917 & $22 / 02 / 1896$ & Prófugo \\
\hline José Israel Muñoz & 1917 & $15 / 09 / 1896$ & Prófugo \\
\hline José Cohen Benjamín & 1918 & $19 / 02 / / 1897$ & Útil \\
\hline Isaac Chouchon Amar & 1920 & $31 / 12 / 1899$ & Prófugo \\
\hline Juan Nahón Álvarez & 1920 & $05 / 10 / 1899$ & Soldado \\
\hline Jacobo Salama Bendelach & 1921 & $28 / 10 / 1900$ & Prófugo \\
\hline Salomón Serruya Amores & 1922 & $07 / 05 / 1901$ & Súbdito \\
británico 144 \\
\hline Aharun Anehin Bescat & 1922 & $15 / 08 / 1901$ & Prófugo \\
\hline Rafael Librate Escart & 1922 & $05 / 10 / 1901$ & Prófugo \\
\hline Samuel Librate Escart & $05 / 10 / 1901$ & Prófugo \\
\hline
\end{tabular}

144 Puede que todavía no fuera súbdito británico (TNA, CO 91/487/20: Case arising out of Legitimacy Ordinance 1927: consolidated petition of Solomon Seruya, Paloma Seruya and Issac Seruya, 1928). 


\begin{tabular}{|l|c|c|c|}
\hline \multicolumn{1}{|c|}{ Nombre } & Reemplazo & $\begin{array}{c}\text { Fecha } \\
\text { nacimiento }\end{array}$ & Situación \\
\hline Isaac Laredo Sixu & 1923 & c. 1902 & Prófugo \\
\hline Abraham Benabida Gapito & 1924 & $09 / 09 / 1904$ & Prófugo \\
\hline Rafael García Elhaquimi & 1925 & $05 / 02 / 1904$ & Prófugo \\
\hline José Sananes Núñez & 1926 & $20 / 08 / 1905$ & Útil \\
\hline Vicente Acris Moreno & 1926 & $07 / 05 / 1904$ & Útil \\
\hline Salomón Salama Bendelan & 1927 & $21 / 07 / 1906$ & Prófugo \\
\hline Moisés Laredo Bendaham & 1927 & $28 / 03 / 1906$ & Prófugo \\
\hline Jacob Benadinas Pinto & 1927 & $11 / 03 / 1906$ & Prófugo \\
\hline Abraham Cohen Buchimol & 1928 & $14 / 11 / 1907$ & Prófugo \\
\hline Marcos Chocron Nahón & 1928 & $30 / 08 / 1907$ & Prófugo \\
\hline Joaquín Bendala & 1929 & $29 / 01 / 1908$ & Prófugo \\
\hline Antonio Acris Moreno & 1929 & $01 / 10 / 1909$ & Prófugo \\
\hline Mesod Salama Bendelac & 1930 & $09 / 07 / 1909$ & Prófugo \\
\hline Adolfo Benbunam & 1930 & $03 / 08 / 1909$ & Prófugo \\
\hline Samuel Sananes & 1930 & $14 / 03 / 1909$ & Útil \\
\hline Francisco Sananes & 1931 & $19 / 06 / 1910$ & Útil \\
\hline Jaime Barfigal Cohen & 1932 & $31 / 08 / 1911$ & Prófugo \\
\hline Alfredo Acris Barbera & 1933 & $21 / 06 / 1910$ & Prófugo \\
\hline Vicente Acris Busto & 1933 & $27 / 01 / 1910$ & Prófugo \\
\hline Antonio Acris Moreno & 1933 & $04 / 12 / 1910$ & Útil \\
\hline Rafael Sananes & 1936 & $15 / 06 / 1915$ & Inútil \\
\hline Sixto Abecasis Domínguez & 1937 & $28 / 06 / 1916$ & Prófugo \\
\hline Mesod Lasry Tocón & 1939 & $26 / 04 / 1918$ & Prófugo ${ }^{145}$ \\
\hline José Cohen Villatoro & 1940 & $15 / 09 / 1919$ & Útil \\
\hline Arturo Benbunam & 1941 & $08 / 02 / 1920$ & Difunto \\
\hline Alberto Cohen Villatoro & 1941 & $25 / 12 / 1920$ & Inútil \\
\hline Abraham Cohen Jalud & 1942 & $09 / 04 / 1921$ & Útil \\
\hline
\end{tabular}

${ }^{145}$ En puridad, don Mesod Lasry no era prófugo, sino que estaba ya sirviendo en el ejército de la República; vid. ApÉnDice Fotográfico. Imagen 1, infra. 


\begin{tabular}{|l|c|c|c|}
\hline \multicolumn{1}{|c|}{ Nombre } & Reemplazo & $\begin{array}{c}\text { Fecha } \\
\text { nacimiento }\end{array}$ & Situación \\
\hline Salvador Sananes Núñez & 1942 & $29 / 05 / 1921$ & Útil \\
\hline Antonio Acris Blanco & 1945 & $20 / 03 / 1909$ & Prófugo \\
\hline Juan Abensur Acris & 1950 & $24 / 06 / 1929$ & Prófugo \\
\hline Manuel Lengui & 1952 & $20 / 09 / 1930$ & Prófugo \\
\hline Alberto Wahnon Fernández & 1955 & $12 / 04 / 1934$ & Prófugo \\
\hline
\end{tabular}

Fuente: AHMFT, Servicios. Quintas. Libro que contiene los alistamientos formados por esta Corporación Municipal desde 1913, La Línea, 1913-1935, 498h; AHMFT, Servicios. Quintas. Libro que contiene los alistamientos formados por esta Corporación Municipal desde 1936, La Línea, 1936-1965, 493h y AHMFT, Gobierno. Ayuntamiento. Libros de sesiones de la Corporación Municipal, 1894-1912.

Por último, uno de los aspectos más destacables de la imbricación de la comunidad hebrea en la vida cotidiana de la ciudad es su presencia en la masonería local ${ }^{146}$. La Línea fue uno de los lugares donde la masonería floreció espectacularmente, sobre todo en el primer tercio del siglo xx: en ella se contabilizaban hasta 16 talleres masónicos que pertenecían a dos obediencias, el Gran Oriente Español y la Gran Logia Española y en ellas militaban una buena parte de los masones del sur de España ${ }^{147}$. De hecho, en un documento recopilado por la policía municipal en 1937 aparecen censadas casi 800 personas adscritas a las dife-

146 También aparecen en menor medida en otras asociaciones como José Cohen Benjamín que era miembro de la asociación Hijos de La Línea en septiembre de 1932 (AHMFT, Servicios. Asociaciones, Hijos de La Linea, La Línea, 1932, s.f.).

147 Véase Antonio Morales Benítez, «Implantación de la masonería en el Campo de Gibraltar durante el primer tercio del siglo xx», Almoraima 17 (1997) págs. 249-263, y Antonio Morales Benítez y Fernando SíGler Silvera, «Gibraltar y la masonería de obediencia española» en La masonería en la España del siglo XX, Tomo I. VII Symposium Internacional de Historia de la Masonería Española, Toledo del 17 al 20 de abril de 1995, ed. José Antonio Ferrer Benimeli (Toledo: Universidad de Castilla-La Mancha, 1996) págs. 911-929. 
rentes logias de La Línea, y esto en una población que contaba con más de 30.000 habitantes en aquellos momentos ${ }^{148}$.

Entre los componentes de estas logias había un número significativo de hebreos no sólo residentes en La Línea sino también en Gibraltar ${ }^{149}$. De los primeros conocemos los trazos de su trayectoria vital en la masonería linense: así León Abecasis Almornis había ingresado en la logia Floridablanca donde había tomado el nombre simbólico de Salomón para pasar luego a la logia Autonomía en 1923 y terminar recalando como primer vigilante en la logia Internacional de Gibraltar en $1926^{150}$; de Mordejay Lengui Beneluz sabemos que se inició en la logia Autonomía en 1926 y causó baja en el taller en 1927, ingresando con posterioridad en la logia Acacia de La Línea, ocupando el cargo de experto en $1933^{151}$; su hermano Mesod Lengui Beneluz también figura militando en la misma logia; Alberto Abecasis González de nombre simbólico Abecasis se afilió en 1911 a la logia linense Regeneración y, por último, Isaac Laredo Sixu también figuraba como masón en la logia Acacia en 1930 con el grado segundo y como primer vigilante en $1933^{152}$.

Junto con ellos perseveraban en las numerosas logias linenses otros hebreos como Samuel Wahnon, carpintero e industrial de Gibraltar, que se inició en la logia Resurrección de La Línea en octubre de 1918, adoptando el nombre simbólico de Saborit y militando posteriormente

148 AHMFT, Servicios. Asociaciones. Masonería local: Lista de masones (copia mecanografiada), La Línea, circa 1937.

149 Otros hebreos de La Línea como Salomón Medina también militaron en la masonería. Medina fue elevado al grado de compañero con el nombre simbólico de Madrid en la logia Abd-el-Asis de Tánger en 1912 (Boletín Oficial del Gran Oriente Español, Año XX, Madrid, núm. 45 de 26 de septiembre de 1912, pág. 167) y aparece después como uno de los masones que toma parte en la fundación de la logia Lixus de Larache en octubre de 1922 con el cargo de secretario; cf. Manuel de PAZ SÁnchez, «En torno a la ideología de los Masones de Larache (1923-1936)», en Masonería, revolución y reacción. Vol. 2, coord. José Antonio Ferrer Benimeli (Alicante: Diputación Provincial de Alicante, Instituto Alicantino de Cultura Juan Gil-Albert, 1990) págs. 837-852.

150 Antonio Morales Benítez, «Gibraltareños en la masonería española (19111936)», Almoraima 29 (2003) págs. 457-473: 466.

151 Morales Benítez, «Gibraltareños en la masonería española», pág. 470.

152 Antonio Morales Benítez, La masonería en el Campo de Gibraltar (19021942). Un espacio de libertad con una nueva sociabilidad democrática (Cádiz: Editorial UCA, 2018) págs. 234-235. 
en la logia Autonomía de La Línea ${ }^{153}$ o Solomón Sabal Tapiero, un hebreo natural de Sevilla, que aparece retratado en un banquete de la logia linense Acacia en $1930^{154}$.

\section{El FINAL DE LA COMUNIDAD HEBREA}

La comunidad había ido disminuyendo en número a lo largo de los años. La presencia inmediata de la colonia británica de Gibraltar suponía una atracción demasiado poderosa para los hebreos de La Línea que, en cuanto mejoraban su situación económica, pasaban con sus familias a vivir en ella. Junto con Gibraltar, la emigración a otros lugares del mundo hacía que la comunidad establecida en La Línea fuera disminuyendo poco a poco. Pero a la erosión que suponía la constante emigración de los hebreos de la ciudad, se unió una circunstancia histórica que acabó por arruinar la vida de la comunidad: el inicio de la Guerra Civil española.

\subsection{La emigración}

Como hemos visto anteriormente, las familias judías presentaban un alto grado de movilidad entre el campo de Gibraltar, Gibraltar y el norte de África. Pero esta movilidad no se limitaba a estas zonas cercanas sino que abarcaba todos los puntos del planeta: la mayor parte de los hebreos de La Línea, como era lógico por su cercanía y sus estrechos vínculos con la comunidad hebrea de Gibraltar, marchaba a la vecina colonia británica y secundariamente también a la metrópoli británica: así Mary

153 Antonio Morales Benítez, «La frontera permeable. Gibraltareños en la masonería española del siglo xx», en Gibraltar, Cádiz, América y la masonería: constitucionalismo y libertad de prensa, 1812-2012. Vol. 1, coords. José Miguel Delgado IDARRETA y Antonio Morales Benítez (Zaragoza: CEHME-Gobierno de Gibraltar, 2014) págs. 209-236.

154 CDMH, SE-Masonería A, Foto 253: Logia Acacia de La Línea de la Concepción. La Línea, 1930 y CDMH, SE-Masonería A, Foto 23: Logia Acacia de La Línea de la Concepción. La Línea, s.f.; vid. ApÉNDICE FOTOGRÁFICO. Imagen 3, infra. 
Beriro en 1879 pasó a vivir en Gibraltar donde residió hasta su muerte ${ }^{155}$ y la familia Acris se trasladó también a Gibraltar a partir de 1882; por su parte, David Salomón Garsón y su familia, una de las primeras que se estableció en la villa, emigró a finales del siglo XIX a la industrial ciudad de Manchester donde se establecieron definitivamente ${ }^{156}$; y del mismo modo procedió Isaac Cazes que se afincó durante unos años junto con su familia en la ciudad de Londres ${ }^{157}$.

Pero otros hebreos de La Línea fueron mucho más allá, cruzaron el Atlántico y emigraron hacia América: Louis Esagui declara haber nacido en La Línea en agosto de 1878 y haber emigrado a Estados Unidos desde Gibraltar en 1887, estableciéndose en Nueva York donde vivió ininterrumpidamente al menos hasta $1924^{158}$; como la mayoría de los emigrantes, llevó con él a su familia, incluso política, con los que residió

155 Pasó a Gibraltar en torno a 1879, donde murió el 30 de octubre de 1917; ("Gibraltar Registry Births Marriages Deaths”, database with images, FamilySearch $(<\mathrm{https}: /$ www.familysearch.org>) Mary Beriro 30 Oct 1917; citing Gibraltar Deaths FHL microfilme 008070620 .

156 Debieron de emigrar después de 1898 ya que en junio de ese año Salomón David Garsón aparece como víctima de un robo en La Línea por parte del súbdito italiano Pedro Luis (Gaceta de Madrid, núm. 209, de 28/07/1898, págs. 430-431). La familia aparece ya en el censo de Inglaterra y Gales de 1911 avecindada en la ciudad de Manchester; ("England and Wales Census, 1911", database, FamilySearch (<https://www. familysearch.org>: 29 June 2019); from "1911 England and Wales census", database and images, findmypast (<https://www.findmypast.com>: n.d.); citing PRO RG 14, The National Archives of the UK, Kew, Surrey).

157 Aparece en el censo de 1911 Isaac Cazes junto con su esposa Judith Hassán y sus hijas; ("England and Wales Census, 1911", database, FamilySearch (<https://familysearch. org/ark:/61903/1:1:XWL9-C9W>: 16 May 2019), Isaac Cazes, Marylebone, London, England, United Kingdom; from "1911 England and Wales census", database and images, findmypast (<https://www.findmypast.com>: n.d.); citing PRO RG 14, The National Archives of the UK, Kew, Surrey.

158 Era hijo de León Esagui, hebreo natural de Tánger; ("United States Passport Applications, 1795-1925", database with images, FamilySearch $(<\mathrm{https}$ ://familysearch. org/ark:/61903/1:1:QV5Y-HWVV>: 16 March 2018), Louis Minon Esagui, 1924; citing Passport Application, New York, United States, source certificate \#498697, Passport Applications, January 2, 1906-March 31, 1925, 2682, NARA microfilm publications M1490 and M1372 (Washington D.C.: National Archives and Records Administration, n.d.). 
en Manhattan al menos hasta $1925^{159}$. Tras él, encontramos a Isabel Acris que marcha a Estados Unidos en 1899 para reunirse con su marido Vicente Jiménez que se había establecido en Brooklyn ${ }^{160}$ o a Abraham Benhayon que emigró a los Estados Unidos desde Gibraltar, llegando en febrero de 1901 y estableciéndose en la ciudad de Nueva York; desde allí llamó a su familia compuesta por su padre Mesod, su madre Rachel Benzaquen, y sus hermanos Rasmia, Ester y Luis que emigraron en 1902, estableciéndose posteriormente todos ellos en Filadelfia ${ }^{161}$.

En 1904 Lola Levy, residente en La Línea, marcha a Nueva York a reunirse con su hermano Benjamín ${ }^{162}$; dos años después, en noviembre de 1906, Leonor y Ester Levy, residentes también en La Línea, emigraron a los Estados Unidos llamadas por el hermano de Ester, Mosés Levy, que vivía ya en Pennsylvania ${ }^{163}$; por último, también encontramos a Carlos Bendayán emigrando a Estados Unidos con el mismo patrón: acogido en casa de su tía Plata Arrobas -que vivía con su yerno Josué Pinto ${ }^{164}$ - en Chicago en 1910, pasa después a Seattle

159 Se unen a la familia su suegra Marian Cedero, que declara haber tenido como última residencia la ciudad de La Línea; ("New York Passenger Arrival Lists (Ellis Island), 1892-1924", database with images, FamilySearch (<https://familysearch.org/ ark:/61903/1:1:JFRR-9MP >: 30 January 2018), Marian Cedero, 1903), y posteriormente León Sedero, su suegro.

160 "New York Passenger Arrival Lists (Ellis Island), 1892-1924", database with images, FamilySearch (<https://familysearch.org/ark:/61903/1:1:JXZK-46N>: 30 January 2018), Isabel Acris, 1899.

161 En el registro del SS Lahn donde embarcan en Gibraltar en 1902, todos declaran tener como última residencia Tánger y nacionalidad marroquí; ("New York Passenger Arrival Lists (Ellis Island), 1892-1924", database with images, FamilySearch (<https://familysearch.org/ark:/61903/1:1:JF2B-5JS>: 30 January 2018), Mesod Benhayon, 1902.

162 "New York Passenger Arrival Lists (Ellis Island), 1892-1924", database with images, FamilySearch (<https://familysearch.org/ark:/61903/1:1:JNM2-WMJ>: 30 January 2018), Lola Levy, 1904.

163 "New York Passenger Arrival Lists (Ellis Island), 1892-1924", database with images, FamilySearch (<https://familysearch.org/ark:/61903/1:1:JF6Q-RZP>: 30 January 2018), Ester Levy, 1906; "New York Passenger Arrival Lists (Ellis Island), 1892-1924", database with images, FamilySearch (<https://familysearch.org/ ark:/61903/1:1:JF6Q-RZR>: 30 January 2018), Leonor Levy, 1906.

${ }^{164}$ En el registro de su matrimonio con Orduena Arrobas en Nueva York en 1906 declara ser español, hijo de Abraham Pinto y Sarah Albo, probablemente de La Línea, 
donde se establece ${ }^{165}$. Y no solo emigraron hacia América del Norte, sino que también encontramos hebreos en el sur del continente americano. Así lo hizo casi toda la familia Salama Bendelac, que emigró a la Argentina a principios del siglo xx: como en los casos anteriores, primero lo hizo el mayor de ellos, Moisés Salama -para evitar el servicio militar en España tal y como vimos anteriormente- y le siguieron luego tres de sus cuatro hermanos restantes, que se establecieron en la ciudad de San Luis, y donde permanecieron hasta el fin de sus días.

Es difícil decir cuál era su relación con su patria natal: fueron los menos de ellos los que conservaron la nacionalidad española -como Mesoda Vibas Ramayón, fallecida en Casablanca en $1944^{166}$, , lo que nos llevaría a pensar que no mantenían demasiados lazos de afectividad para con ella ni para con España a pesar de que todos ellos eran de origen sefardí. Salvador Salama, desde la Argentina, recuerda cómo nunca más volvió a La Línea:

Yo no volví más a La Línea, así que no volví a ver a mis padres. Moisés - en cambio- viajó a ver la tumba de mi madre, porque soñó una vez que ella le pedía que fuera a verla ${ }^{167}$.

El caso es que la mayoría de ellos optaron por la naturalización en sus respectivos países de adopción. Los hebreos que volvieron a la plaza de Gibraltar por razones económicas o por razones políticas solicitaron

aunque la lectura no es demasiado buena; ("New York, New York City Marriage Records, 1829-1940", database, FamilySearch (<https://familysearch.org/ark:/61903/1:1:24989LJ $>$ : 10 February 2018), Joshua Pinto and Orduena Arrobas, 16 Sep 1906; citing Marriage, Manhattan, New York, New York, United States, New York.

165 Era hijo de Manuel Bendayán, natural de La Línea, y de Mary Arrobas, de Gibraltar. Casado en Tacoma (Washington) en 1915; ("Washington, Pierce County Marriage Returns, 1891-1938", database with images, FamilySearch (<https://familysearch. org/ark:/61903/1:1:QGTQ-89SV>: 19 April 2018), Charles Bendayan and Bula Martin, 23 Sep 1915; citing Marriage, Pierce, Washington, United States, Washington State Archives, Puget Sound Region, Bellevue.

166 Nació el 26 de enero de 1881 en La Línea, hija de Mesod y Rachel; murió en Casablanca el 23 de enero de 1944 (BOE, núm. 232 de 19/08/1944, pág. 3.247).

167 Bentolila, «La colectividad judía», pág. 184. 
la nacionalidad británica a lo largo del siglo $\mathrm{xx}^{168}$ : así lo hicieron en 1918 varios miembros de la familia Cazes nacidos en La Línea a finales del siglo xIX y principios del $\mathrm{xx}^{169} \mathrm{y}$ del mismo modo procedieron los miembros de la familia Bensadon solicitando su naturalización como súbditos británicos en los años 50 170. Todavía en las últimas décadas del siglo pasado siguieron naturalizándose algunos de los restantes hebreos nacidos en La Línea como los miembros de la familia Bentata ${ }^{171}$, Vincent Acris ${ }^{172}$ o Sixto Abecassis Domínguez ${ }^{173}$. Por su parte, los hebreos emigrados a Norteamérica también se naturalizaron en su país de acogida: Louis Esagui se convirtió en ciudadano estadounidense en diciembre de $1893{ }^{174}$ y Abraham Benhayón pidió su naturalización por primera vez en febrero de $1914{ }^{175}$.

168 Para la cuestión de la ciudadanía de los nacidos en la colonia de Gibraltar, véase Stephen Constantine, Community and identity. The making of modern Gibraltar since 1704 (Manchester: Manchester University Press, 2009).

169 Se naturalizan en primer lugar Isaac Joseph Cazes, nacido en La Línea, y junto con él sus hijos Luna, Rachel y Gimol Julia en 1918 (TNA, HO, 334/249/50). Posteriormente lo haría Jacob Cazes en 1919 (TNA, HO 334, 249/57).

170 John, Joseph y Mario Bensadon en 1956 (TNA, HO 334/288/16482, TNA, HO 334/288/16483 y TNA, HO 334/288/16484); Ana Bensadon y Moses Bensadon en 1983 (TNA, HO, 334/3790/1061487 y TNA, HO 334/3807/1065729).

171 Donna Bentata en mayo de 1933 (TNA, HO, 334/251/1241).

172 Vincent Acris en julio de 1983 (TNA, HO 334/3598/1012732).

173 Sixto Abecasis en junio de 1984 (TNA, HO, 334/3966/110543).

174 "United States Passport Applications, 1795-1925", database with images, FamilySearch (<https://familysearch.org/ark:/61903/1:1:QV5Y-HWVV>: 16 March 2018), Louis Minon Esagui, 1924; citing Passport Application, New York, United States, source certificate \#498697, Passport Applications, January 2, 1906-March 31, 1925, 2682, NARA microfilm publications M1490 and M1372 (Washington D.C.: National Archives and Records Administration, n.d.).

${ }^{175}$ La nacionalización le fue negada posteriormente por haber esgrimido su condición de español para no incorporarse al ejército estadounidense en 1917 ("New York, County Naturalization Records, 1791-1980", database with images, FamilySearch (<https://familysearch.org/ark:/61903/1:1:QP8J-P7ZR>: 7 November 2018), Abraham Benhayon, 1914; citing Naturalization, New York, United States, citing various county clerk offices of New York; FHL microfilm 005411690. 


\subsection{La Guerra Civil}

Hay un segundo factor, junto con la emigración, que hizo que la comunidad desapareciera de la ciudad: la Guerra Civil española. La Línea fue ocupada en los primeros días de la guerra lo que provocó que muchos de los españoles que se decantaron por la República o tenían simpatías por ella abandonaran la ciudad en dirección a Gibraltar; junto con ellos los súbditos británicos que vivían en la ciudad también la abandonaron en masa, llegando a reunirse un número considerable de refugiados en la colonia ${ }^{176}$. Entre ellos se encontraba parte de la pequeña comunidad hebrea de La Línea, bien porque no era partidaria de los alzados o bien porque la retórica de las nuevas autoridades de la ciudad tenía cierto tono antisemita que no auguraba nada bueno para los hebreos:

Estamos en la España nueva, queremos una España grande, y los que por desgracia vivimos en este último pueblo de nuestra Patria, tenemos que desprendernos de las garras de ese Peñón, triste oscuro y fatídico, donde una masa Judía nos mueve a su antojo, disfruta de nuestro maravilloso clima y se ríe de nuestra desgracia ${ }^{177}$.

Así pues, en la ciudad quedaron muy pocos miembros de la comunidad. En el registro de cédulas personales realizado en torno a 1938 ya solo aparecen seis individuos -cuatro hebreos y dos descendientes de hebreos- lo que nos indica que la comunidad había quedado reducida a su mínima expresión ${ }^{178}$.

176 Aproximadamente unos 4.000 hombres, mujeres y niños; $c f$. George HiLls, Rock of contention. A History of Gibraltar (Londres: Robert Hale \& Company, 1974) pág. 411. Julio Ponce Alberca (Gibraltar and the Spanish Civil War, 1936-39. Local, National and International Perspectives [London: Bloomsbury, 2016] pág. 92) da la misma cifra de súbditos británicos refugiados en la plaza.

177 AHMFT, Gobierno. Alcaldía. Bandos municipales, La Línea, 3 de diciembre de 1936. Para la actitud del nuevo régimen para con los judíos, véase Haim AvNi, España, Franco y los judios (Madrid: Altalena, 1982).

178 AHMFT, Servicios. Población. Padrón de cédulas personales, La Línea, circa 1938, s.f. 
Tabla 8

Hebreos en La Línea en 1938

\begin{tabular}{|c|c|}
\hline Nombre & Domicilio \\
\hline Ignacia Acris Busto & Calvo Sotelo, 17 \\
\hline Alfredo Acris Pérez & González de la Vega, 17 \\
\hline Perla Attias & Sevilla, 15 \\
\hline José Benatar & Lisboa s/n \\
\hline B. Bensusan & San Luis, 6 \\
\hline Juda Cohen & Mercado s/n \\
\hline
\end{tabular}

Fuente: AHMFT, Servicios. Población. Padrón de cédulas personales. La Línea, circa 1938.

De los que se refugiaron en el Peñón algunos, los menos, abandonaron la colonia ${ }^{179}$ y se enrolaron en las milicias de la República como José Cohen Benjamín, afiliado a la UGT y al Partido Comunista, que fungió como cabo en el batallón Pablo Iglesias en el frente de Málaga ${ }^{180}$ o como Mesod Lasry Tocón que luchó también en el bando republicano hasta el fin de la guerra ${ }^{181}$; mientras que otros vecinos de La Línea permanecieron en Gibraltar donde tenían parientes que los acogieron como Menahem Creciente que pasó a la plaza con su mujer Angelina Morales en julio de $1936^{182}$ o Haim Abensur que hizo lo propio con su

179 El relato novelado de cómo abandonaron Gibraltar estos españoles en dirección a Málaga puede leerse en Ángel María DE LERA, Las últimas banderas (Barcelona: Planeta, 1967) págs. 344-346.

180 Era natural y vecino de La Línea, nacido el 19/02/1897, hijo de Isaac y Simi (AHMFT, Servicios. Quintas. Libro que contiene los alistamientos formados por esta Corporación Municipal desde 1913, La Línea, 1913-1935, h. 99r); estaba casado y trabajaba en Gibraltar como jornalero (Fernando Bravo. Batallones que defendieron el frente de Abdalajis. Recuperado de <http://fbravoconejo.blogspot.com> [consultado el 30 de julio de 3019]).

181 Testimonio oral de doña Juana Lasry.

182 "Gibraltar Registry Births Marriages Deaths", database with images FamilySearch (<https://familysearch.org $>$ ) Angelines Creciente 4 Oct 1937; citing Gibraltar Deaths FHL microfilme 008070620. 
familia en esas mismas fechas ${ }^{183}$; también hubo quien prefirió poner tierra por medio y emigró al norte de África, sobre todo a Tánger como Isaac Laredo Sixu que posteriormente emprendió allí una carrera non sancta en la década de los cincuenta ${ }^{184}$ o Mesod Lengui cuya última noticia parece situarle en la misma ciudad junto con su hijo Manuel prófugo del servicio militar en esa misma década; también recaló en Tánger el hebreo sevillano Salomón Sabal Tapiero pero por poco tiempo antes de emigrar a los Estados Unidos con toda su familia ${ }^{185}$.

A pesar de que, en los meses siguientes al comienzo de la guerra, los refugiados -sobre todo los súbditos británicos- comenzaron a volver a La Línea, la mayoría de los hebreos optó por no hacerlo. Es posible que temieran alguna represalia o que el nuevo gobierno no les inspirara mucha confianza. Obviamente era una conclusión lógica sobre todo para el grupo de masones judíos que militaban en las logias linenses pues la persecución que se desató contra los miembros de la masonería local hizo que casi todos ellos fueran encausados y juzgados en rebeldía por el Tribunal Especial de Represión de la Masonería a lo largo del año 1942: así Mesod Lengui es condenado en rebeldía a 12 años y un día de reclusión menor en marzo ${ }^{186}$, mientras que su hermano Mordejay es

183 Véase en The Adrian Moss Family Tree (accesible en <https://sites.google.com/ site/mossfamilybelper/mums-family> [consultado el 30 de julio de 2019]).

184 Aparece como dueño de una embarcación llamada Imar con la que alijaba tabaco en las costas de Cádiz, Málaga y Huelva en la década de los cincuenta (BOE, núm. 331 de 27/11/1954, pág. 3.891; BOE, núm. 48 de 17/02/1955, pág. 487; BOE, núm. 284 de 11/10/1955, pág. 3.384; BOE, núm. 241 de 23/09/1957, pág. 5.163 y BOE, núm. 25 de 29/01/1959, págs. 1.744-1.745).

185 Salomón Sabal Tapiero se refugió en Gibraltar y se trasladó posteriormente a Tánger. En septiembre de 1938 embarcó en Gibraltar en el SS Roma y emigró a los Estados Unidos junto su hermana Mesodi Sabal, su mujer Matilde Yaffer y sus cinco hijos; ("New York, New York Passenger and Crew Lists, 1909, 1925-1957", database with images, FamilySearch (<https://familysearch.org/ark:/61903/1:1:242F-PL7>: 12 March 2018), Salomon Sabal Tapiero, 1938; citing Immigration, New York, New York, United States, NARA microfilm publication T715 (Washington, D.C.: National Archives and Records Administration, n.d.).

186 Hay tres fichas de encausado de Mesod Lengui (CDMH, TERMC, Fichero, 77,2715352; CDMH, TERMC, Fichero 74,2409461 y CDMH, TERMC, Fichero 77,2718808). Su condena aparece en BOE, núm. 90 de 31/03/1942, pág. 1.648. 
condenado a 16 años de reclusión menor tres meses después ${ }^{187}$; en octubre de ese mismo año son condenados Isaac Laredo Sixu a 16 años de reclusión menor ${ }^{188}$ y León Abecasis Almornis a la misma pena de cárcel ${ }^{189}$. Los únicos masones que escaparon con cierta suerte fueron Isaac Belilo Abecassis, otro de los hebreos avecindados en La Línea, que resultó absuelto en 1941 por el Tribunal Regional de Responsabilidades Políticas ${ }^{190}$ y Alberto Abecasis González, residente ya en Gibraltar, cuyo sumario fue archivado en 1945 por el mismo Tribunal ${ }^{191}$.

\section{Conclusiones}

Daniel Rozenberg apuntaba en L'Espagne contemporaine et la question juive que el conocimiento que tenemos de las primeras comunidades judías establecidas en España en el siglo XIX era muy fragmentario:

En résumé, la connaissance des premiers établissements juifs de l'époque contemporaine est lacunaire. Les communautés identifiées ne présentent pas de réelle continuité dans le temps. On ignore ce que sont devenus la pluspart de leurs membres ainsi que leurs descendants. À travers le recoupement des témoignages, quelques échos de presse ou encore divers ouvrages emerge une represéntation fragmentaire permettant tout au plus de reconstituer le parcours de personnalités notoires, de repérer certains évènements prenant valeur de symbole dans l'histoire

187 Hay tres fichas de encausado de Mordejay Lengui (CDMH, TERMC, Fichero, 77, 2715353; CDMH, TERMC, Fichero, 77, 2719633 y CDMH, TERMC, Fichero, 74, 2409461). Su condena aparece en BOE, núm. 178 de 27/06/1942, pág. 2.757.

188 Hay tres fichas de encausado de Isaac Laredo (CDMH, TERMC, Fichero, 70,2213473; CDMH, TERMC, Fichero 74,2409352 y CDMH, TERMC, Fichero 77,2715160). Su condena aparece en BOE, núm. 329 de 25/11/1942, pág. 4.316.

189 De León Abecasis hay cuatro fichas de encausado (CDMH, TERMC, Fichero, 77,2700056: CDMH, TERMC, Fichero 70,2200074; CDMH, TERMC, Fichero 70,2200075 y CDMH, TERMC, Fichero 74,2400029). Su condena aparece en BOE, núm. 5 de 05/01/1943, pág. 46 .

190 BOE, núm. 24 de 24/01/1942, pág. 515 y BOP, núm. 54 de 18/11/1941. Probablemente es el hijo de Azaar Belilo y Bonina Abecasis, nacido en Gibraltar el 22/02/1892.

191 CDMH, TERMC, 12683: Sumario 540-45 contra Alberto Abecasis González por delito de masonería. 
du judaïsme renaissant et enfin de cerner les conditions générales dans lesquelles se sont réalisées ces «retours» en Espagne ${ }^{192}$.

En este artículo hemos querido mostrar brevemente cómo nació y se desarrolló una de estas comunidades -quizá una de las primeras de España desde su expulsión- a lo largo de sus aproximadamente ochenta años de historia. Hemos visto cómo la pequeña comunidad hebrea de La Línea fue medrando durante los primeros años hasta acabar prácticamente extinguida por la emigración continua de sus miembros y por el estallido de la Guerra Civil española. A diferencia de otras comunidades similares, como la ceutí o la melillense que se afianzaron en sus ciudades y sobrevivieron hasta nuestros días, la comunidad hebrea de La Línea desapareció casi por completo dejando solamente como recuerdo de su existencia un pequeño número de apellidos hebreos diseminados entre la población y un cementerio casi desconocido ${ }^{193}$.

Recibido: 15/12/2019

Aceptado: 13/02/2020

192 Danielle Rozenberg, L'Espagne contemporaine et la question juive. Les fils renoués de la mémoire et de l'histoire (Toulouse: Presses universitaires du Mirail, 2006) pág. 100.

193 Sin embargo, puede que haya una curiosa pervivencia de la comunidad judía en la ciudad: la expresión como cualmente que se utiliza habitualmente en el habla popular de La Línea significando 'como si, como justificante de' puede tener que ver como el uso del adverbio cualmente en el judeoespañol; $c f$. Carmen Hernández GonzáLEz, «Observaciones en torno al proceso de gramaticalización de la forma judeoespañola 'cualmente'», Philologia Hispalensis 32:1 (2019) págs. 77-94. 


\section{APÉNDICE FOTOGRÁFICO}

\section{Imagen 1}

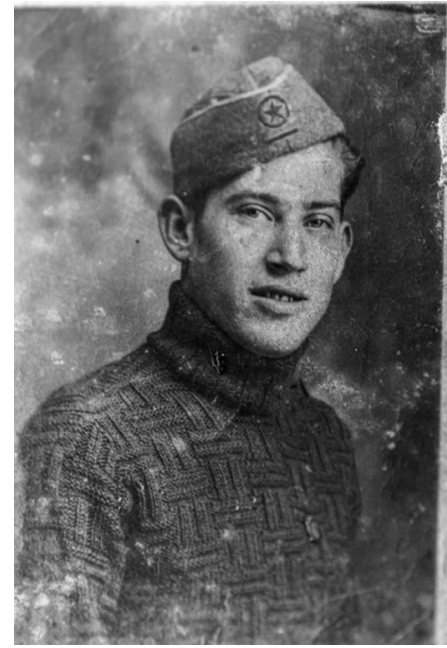

D. Mesod Lasry Tocón, circa 1936

(Foto cortesía de Doña Juana Lasry)

\section{Imagen 2}

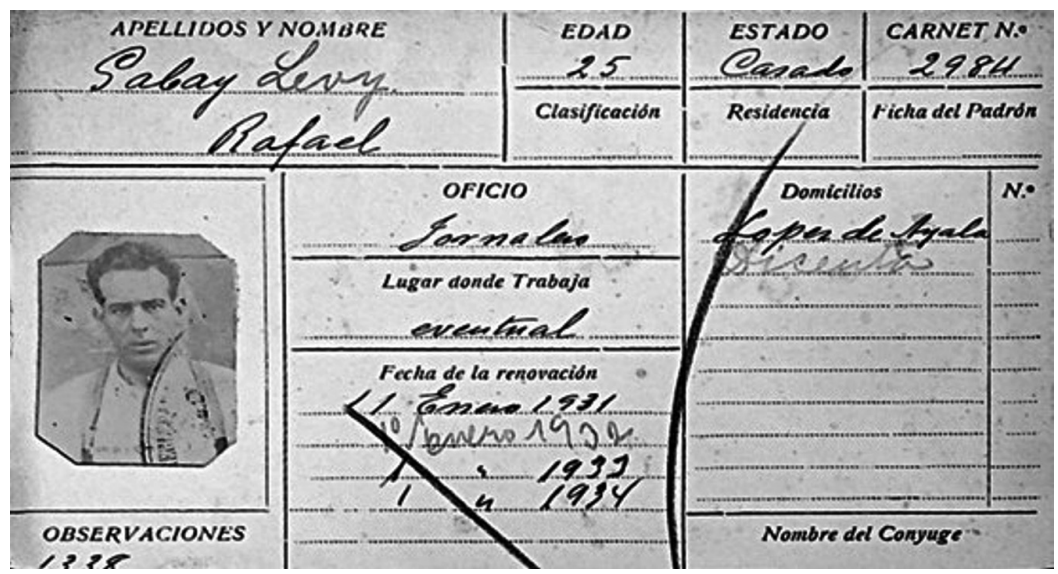

D. Rafael Gabay Levy

AHMFT, Servicios. Población. Identidad local, 1931-1934, núm. 2.984 


\section{Imagen 3}

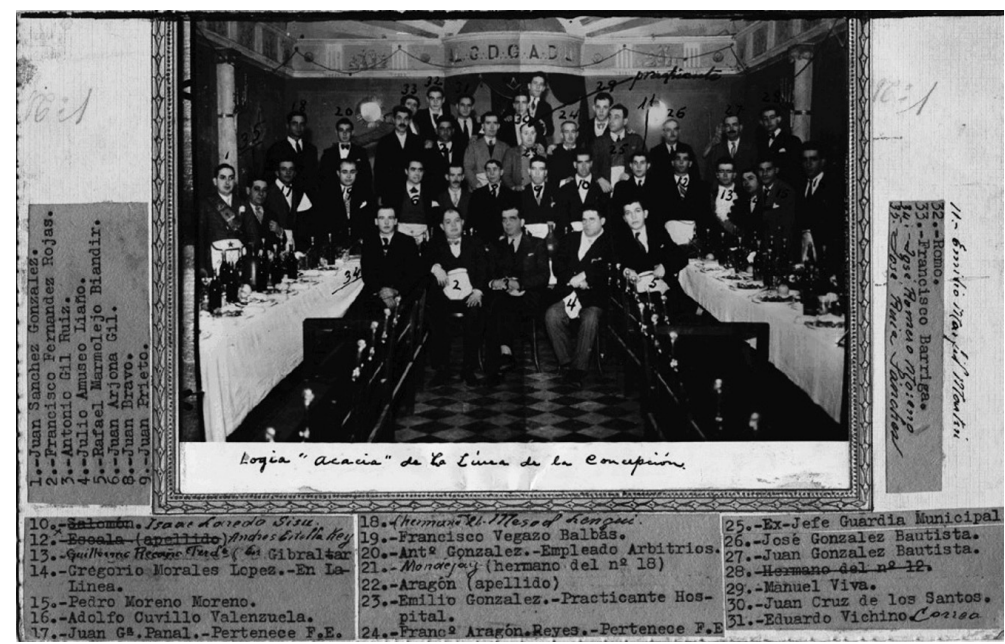

AHMFT, Servicios. Asociaciones. Masonería, Logia Acacia de La Línea de la Concepción, circa 1930 (Es copia de CDMH, SE-MASONERIA_A, FOTO. 23: Banquete de la Logia Acacia. La Línea, s.f.). Con los números 18 y 21 aparecen los hermanos Lengui Beneluz. También aparece consignado Isaac Laredo Sixu con el número 10 pero en nuestra opinión es probablemente Salomón Sabal Tapiero.

\section{Imagen 4}

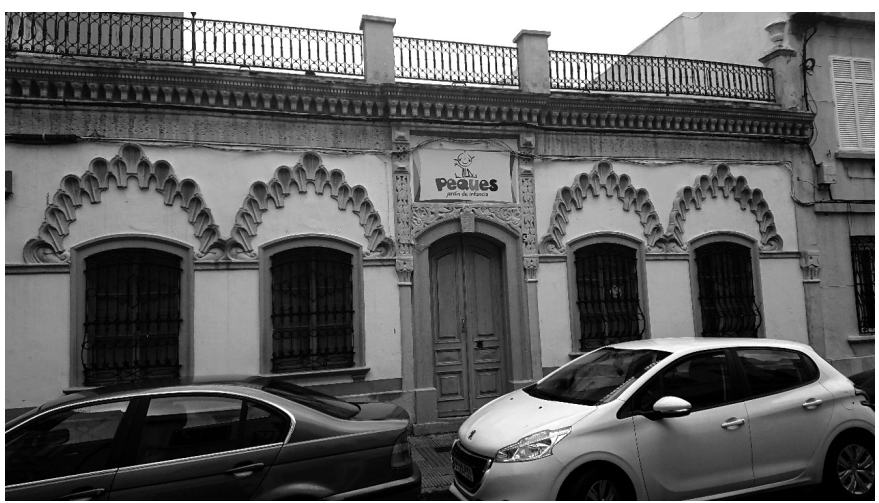

Calle del Teatro, núm. 5

(Foto cortesía de D. José Martínez Téllez) 


\section{Imagen 5}

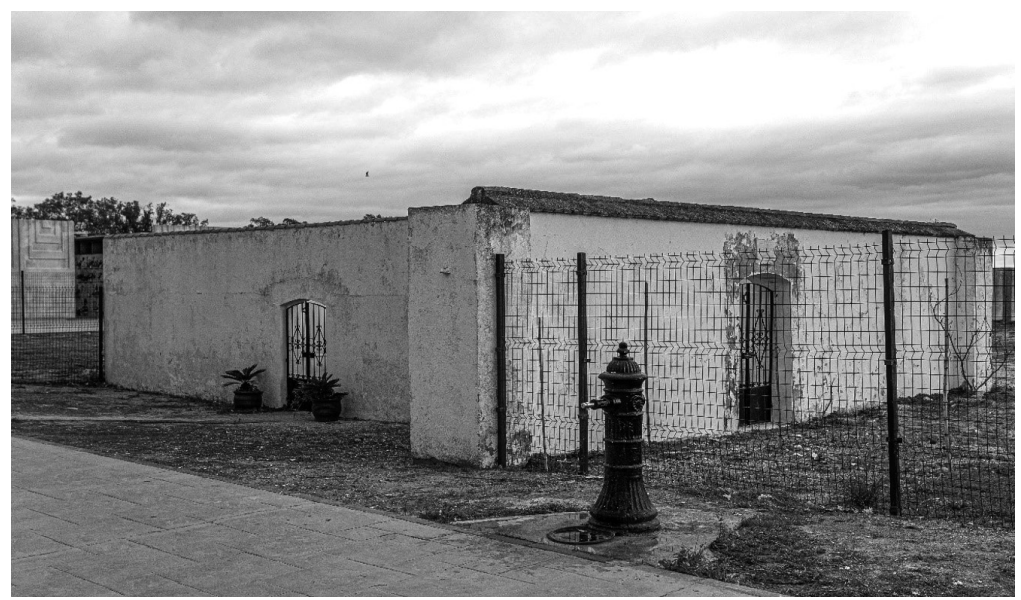

Vista panorámica del cementerio hebreo (Foto cortesía de D. José Manuel Roca)

Imagen 6

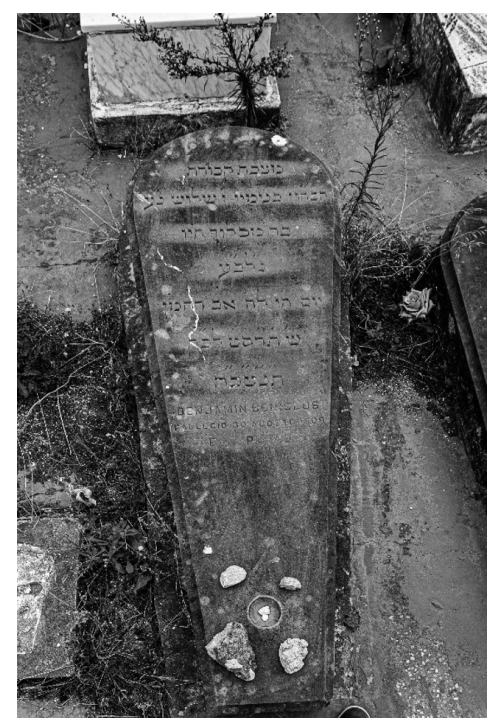

Lápida de D. Benjamín Benislus (1909) (Foto cortesía de D. José Manuel Roca)
Imagen 7

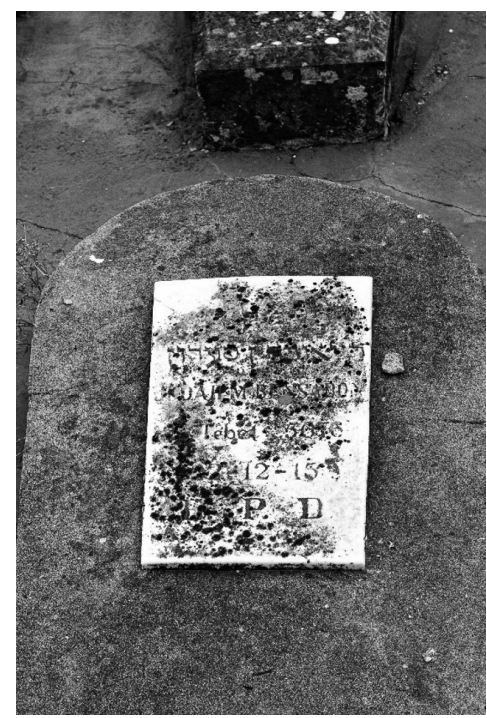

Lápida de D. Judah Bensadón (1913) (Foto cortesía de D. José Manuel Roca) 